\title{
WELD PENETRATION AND DEFECT CONTROL
}

Final Report

Grant DEFG0788ER12817A

\author{
Bryan A. Chin \\ Materials Engineering \\ Department of Mechanical Engineering \\ Auburn University \\ Auburn, AL 36849 \\ May 15, 1992
}

Document \#WP15D0EF

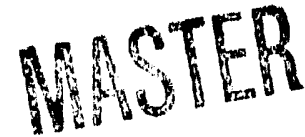


TABLE OF CONTENTS

I. SUMMARY OF COMPLETED RESEARCH . . . . . . . . . . . . 4

II. INTRODUCTION ..................... 5

III. CURRENT STATUS OF RESEARCH . . . . . . . . . . . . 6

III.1 Experimental Setup . . . . . . . . . . . . 6

III.2 Data Display Modes . . . . . . . . . . . . . . . . 8

III.3 Numerical Simulation of the Welding Process . . . . . . . 9

III.4 Shielding Gas Related Penetration Experiments . . . . . . 15

III.5 Gradient Technique Experiments . . . . . . . . . . . . 17

III.6 Minor Element Experiments . . . . . . . . . . . . . . 18

III.6.1 Arc Melter Experiments ............ 20

III.6.2 Minor Element Insert Experiments ........ 23

III.7 Penetration Control based on Bead Width Control . . . . . 26

III.8 Correction of Initial Joint offset . . . . . . . . . . 28

III.9 Joint Gap Determination ............... 28

III.10 Summary of Experimental Results ............. 33

III.11 Publications and Presentations .......... 34

III.12 Awards . . . . . . . . . . . . . . . . . 35

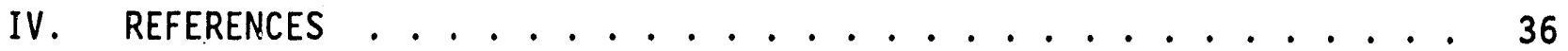

\section{DISCLAIMER}

This report was prepared as an account of work sponsored by an agency of the United States Government. Neither the United States Government nor any agency thereof, nor any of their employees, makes any warranty, express or implied, or assumes any legal liability or responsibility for the accuracy, completeness, or usefulness of any information, apparatus, product, or process disclosed, or represents that its use would not infringe privately owned rights. Reference herein to any specific commercial product, process, or service by trade name, trademark, manufacturer, or otherwise does not necessarily constitute or imply its endorsement, recommendation, or favoring by the United States Government or any agency thereof. The views and opinions of authors expressed herein do not necessarily state or reflect those of the United States Government or any agency thereof. 


\section{LIST OF FIGURES}

Figure 1. Experimental Setup . . . . . . . . . . . . . 7

Figure 2. Schematic of Data Acquisition Systern ............ . 7

Figure 3. Isothermal Contour Map ..................... . 8

Figure 4. Temperature Distribution along a Horizontal Line..... . 9

Figure 5. Computed Temperature Distributions - Surface Form . . . . . 11

Figure 6. Computed Temperature Distributions - Isotherms . . . . . . . 12

Figure 7. Computed Temperature Distributions at a Cross-section . . . 13

Figure '8. Effect of Surface Inclusion on Temperature Distribution . . 14

Figure 9. Linescans - Argon and Helium Shielding Gas ......... . . 16

Figure 10. Temperature Gradient - Argon and Helium Shielding Gas . . . 16

Figure 11. Penetration-Gradient Relation, Function of Gas Composition . 16

Figure 12. Effect of In-Process Shielding Gas Change ........ . 17

Figure 13. Gradient Technique ................... . 18

Figure 14. Computed Weld Pool Front for a Step Change in Thickness . . 19

Figure 15. Comparison of Measured and Computed Bead Widths . . . . . . 19

Figure 16. Minor Element Effects on Weld Pool Convective Flow . . . . . 21

Figure 17. Schematic of Arc Melter . . . . . . . . . . . . . . . 22

Figure 18. Minor Element Strip Fitup . . . . . . . . . . . . . . . . . . . 22

Figure 19. Temperature Gradient for Weld with Horizontal Minor

Element Strip.................. 23

Figure 20. Steel Plates for Minor Element Insert Experiments . . . . . 24

Figure 21. Temperature Gradient for Aluminum Insert Experiments . . . . 25

Figure 22. Temperature Gradient for Iron Sulfide Insert

Experiments .............. 25

Figure 23. Temperature Gradient for Plate with Step Thickness $\ldots . .25$

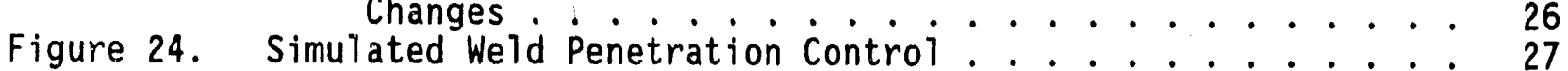

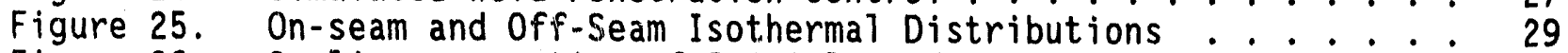

Figure 26. On-line correction of Initial Weld-Joint offset . . . . . 30

Figure 27. Infrared Intensity Distribution across a Joint . . . . . . . 31

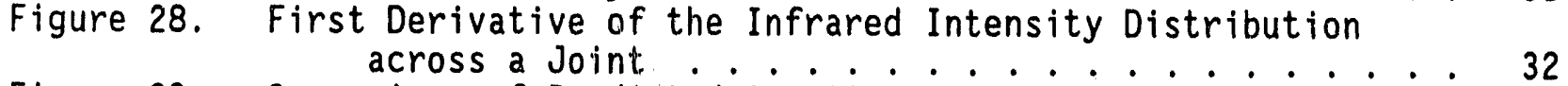

Figure 29. Comparison of Predicted Gap Sizes

Figure 30. Tracking of Joints with a Gap . . . . . . . . . . . . . . . . 33 


\section{SUMMARY OF COMPLETED RESEARCH}

During the last year, progress was made under this research grant in identifying weld perturbations which affect weld quality. Using changes in the temperature gradient, methods of identifying and measuring gaps which occur due to fixturing errors, part tolerance problems or during heat up of the plates were completed. This work led to the ability to produce quality welds in plates containing as large a gap as $1.016 \mathrm{~mm}(0.04 \mathrm{in})$ while following the seam.

Predictions from numerical simulation studies compared we 11 with experimental observations. The three dimensional transient heat transfer equation was discretized in space using finite differences and in time using the Runge-Kutta technique. With the help of three enmeshed grids, temperature distributions were predicted for normal cases as well as in the presence of surface inclusions.

The effect of ..unor elements on weld penetration is well known. Until recently, their effect on the infrared intensity distributions was however not well understood. During the course of our investigation, our research team has shown that minor elements have a unique effect on the temperature gradient. This effect cannot be seen in the presence of other welding perturbations such as welding current changes or plate thickness changes.

Further investigations were carried out on the weld penetration indicators. The feasibility of using each of these indicators for on-line penetration control was investigated. The procedures for computing each of these indicators were streamlined to reduce the computation time. Bead width was one of the methods used for on-line penetration control. A penetration control software was developed for on-line weld penetration control using the computed bead width as the error signal and the welding current as the control parameter. 


\section{Hatropuction}

Highly engineered designs increasingly require the use of improved materials and sophisticated manufacturing techniques. To obtain optimal performance from these engineered products, improved weld properties and joint reliabilty are a necessity. This requirement for improved weld performance and reliability has led to the development of high-performance welding systems in which pre-programmed parameters are specified before any welding takes place. These automated systems however lack the ability to compensate for perturbations which arise during the welding process. Hence the need for systems which monitor and control the in-process status of the welding process.

Automated welding systems have been developed for processes such as gas metal and gas tungsten arc welding. Typically these systems have been designed for special applications such as welding inaccessible areas of ship hulls [13-16] and missile trajectory-control vanes [17]. Torch offset and non-uniform weld penetration are the most often encountered weld quality problems in preprogrammed automated welding systems.

Different techniques are now in use for weld quality control in automated welding processes. These techniques either use a special sensor or use numerical methods such as statistical process control [19] or special techniques [37-48] such as 'Through-the-arc sensing' or 'Laser Striping'. The success of these techniques depends on the efficiency of the sensing and feedback/control cycle. Some of the more common sensors include optical charge-coupled-device cameras [20-27], acoustic emission sensors [28-30], ultrasonic sensors [31-35], tactile sensors [36] and infrared sensors [63-67].

Optical charge-coupled device cameras are the most commonly used sensors. These cameras have been used for different purposes such as determining weld pool contours [20], open loop control of the welding process [21, 22], pressure vessel welding [23,24], guiding automated roving vehicles [25], real time control of robots [26] and for guiding electrodes [27].

Acoustic emission sensors have been used in real time for weld quality monitoring in gas metal welding [28-30]. Ultrasonic sensors are being increasingly used [31-35] to detect incomplete sidewall fusion, porosity, weld bead geometry [34] and torch offset [35].

Other control iechniques include magnetic control of arcs for positioning [49-56] and penetration control through puddle characterization [57-62]. Thermal characteristics of welding processes have been studied using infrared sensors [63-67]. The infrared radiation emitted from the surface of the welded plates has been used to determine the cooling rates [65]. One or more of the sensors discussed above have been used in the design of intelligent welding systems that use pattern recognition techniques [68-72]. There have beer several theoretical attempts at predicting the temperature distributions during the welding process. Weld pool surface temperature distributions have been predicted for both an autogenous as well as a non-autogenous GTA welding process [77-79].

Prior welding research at Auburn has been based on infrared sensors. Previous investigations by the authors suggest that it is possible to implement 
seam tracking, contaminant control, monitoring weld pool size/position and weld penetration using a single sensor [80-97]. These sensors have been used for seam tracking butt joints with or without a V-groove. Results presented in the next section highlight last year's progress in the task of weld penetration and defect control using infrared sensors.

\section{CURRENT STATUS OF RESEARCH}

\section{III.2 Experimental Setup:}

Figure 1 shows the welding and infrared camera equipment. The infrared camera, shown mounted on the torch assembly, monitors the temperature distribution around the weld pool. A custom built interface transfers the information from the camera to the computer (see Figure 2) for analysis and feedback of appropriate corrective action. In all experiments, gas tungsten arc welding was performed with a Miller Synchrowave $500 \mathrm{AC} / \mathrm{DC}$ power source and a water cooled torch. The torch was manipulated by an ESAB X-Y positioning table. This positioning table was controlled by a Hewlett Packard series 320 computer through an HP3497A data acquisition/control unit. The infrared radiation which characterizes the thermal distribution of the plates being welded, was measured by an Inframetrics mode 1525 Infrared camera. The infrared camera determines the temperature distribution by sampling a portion of the emitted energy within a wavelength band of 8 to 12 micrometers. The infrared image from the camera was transferred to the controlling computer in a digital format. Fach scan of the camera was transferred as a frame consisting of $250 \times 192$ discrete infrared intensity measurements. These measurements are a function of the local absolute temperatures and are in a digital format, stored as numbers ranging from 0 to 255.

The welding was performed using $6.35 \mathrm{~mm}(0.25$ in) thick AISI 1008 steel plates of size $304.8 \mathrm{~mm} \times 304.8 \mathrm{~mm}$ (12 in X $12 \mathrm{in}$ ). These plates were prepared by sand blasting before welding. The welding parameters have been given in Table 1. Specific equipment needs for each of the objectives are discussed individually in the following sections.

Table 1. Welding Parameters

Torch Speed
Shielding Gas
Current
Voltage
Electrode

Torch Speed

Current

Electrode

\author{
$2.667 \mathrm{~mm} / \mathrm{s}$ (6.3 in/min) \\ Argon, $18.87 \mathrm{it} / \mathrm{min}(40 \mathrm{cfh})$ \\ $200 \mathrm{~A} \quad \mathrm{DC}$ \\ $20 \mathrm{~V}$ \\ Negative, EWTh-2, $3.175 \mathrm{~mm}$
}




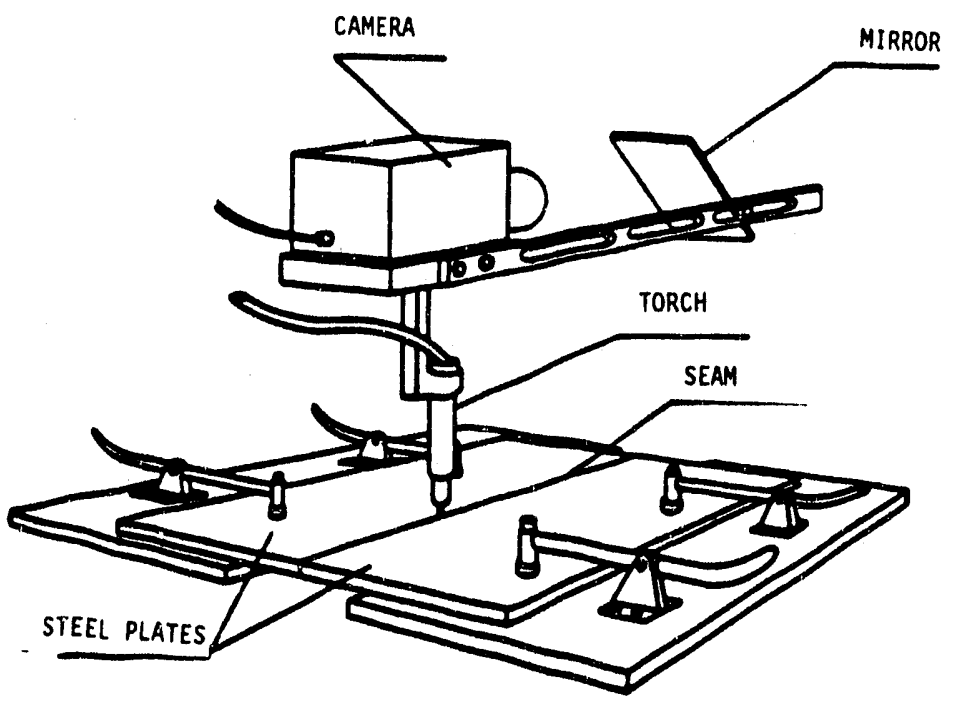

Figure 1. Experimental Setup

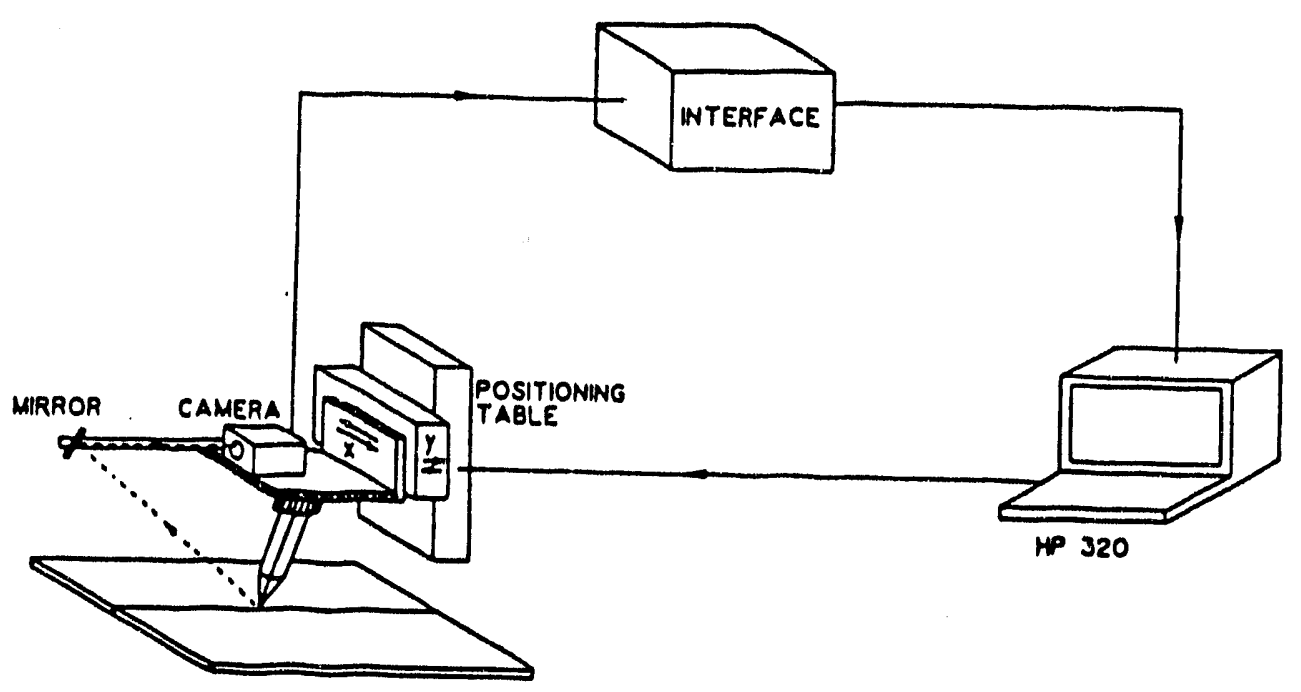

Figure 2. Schematic of Data Acquisition System 


\section{III.2 Data Display Modes:}

The surface temperature distributions of the plates being welded can be displayed in different ways. The two methods that were used to display the data for analys is were - isothermal contours (regions of equivalent temperature) and linescans (thermal profile along a line on the plate, transverse to the direction of torch motion). Figure 3 shows the isothermal temperature distribution of a weld made on a $6.35 \mathrm{~mm}(0.25 \mathrm{in})$ thick AISI 1008 steel plate. A specific line (Row $=50$ ) of that isothermal contour map is displayed in the line scan mode (Figure 4).

The isothermal contour map consists of several color bands, each corresponding to a range of temperatures $(\mathrm{Black}=$ coldest, Magenta $=$ hottest $)$. Linescans reveal local temperature changes, whereas the isothermal contour maps generally show macroscopic changes in the temperature distribution.

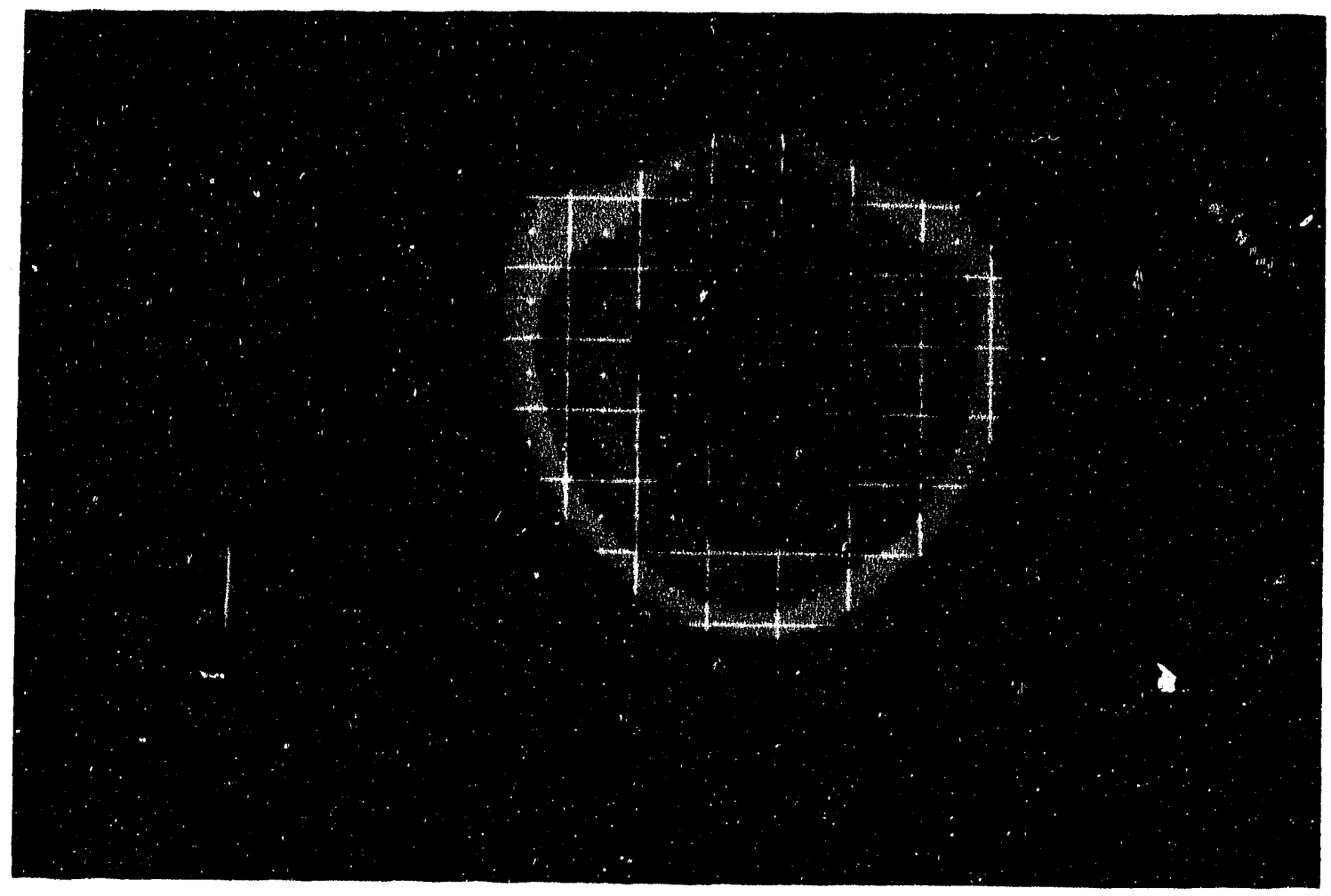

Figure 3. Isothermal Contour Map 


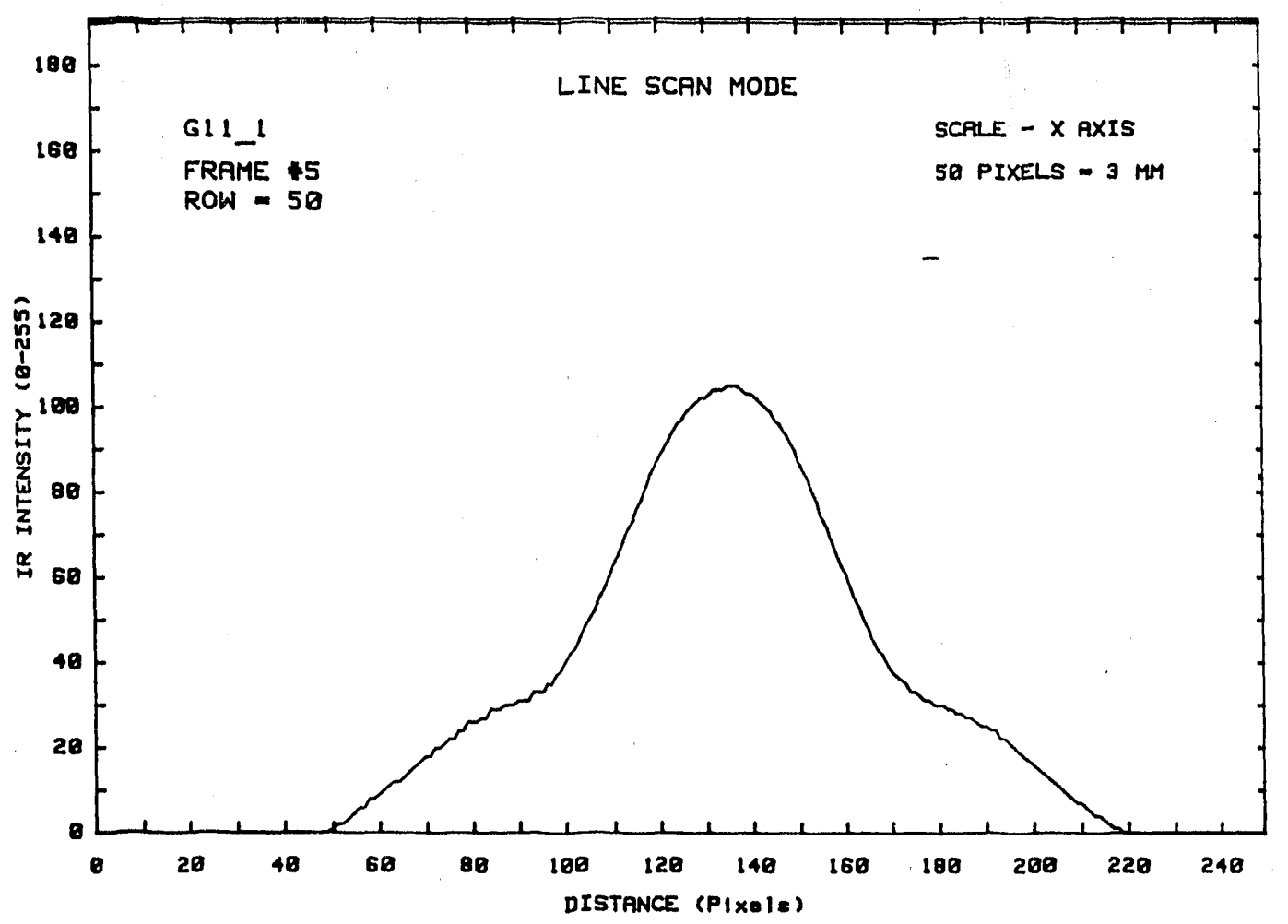

Figure 4. Temperature Distribution along a Horizontal Line

\section{III.3 Numerical Simulation of the Welding Process}

A numerical simulation based on the three dimensional transient heat transfer model developed by UTe and Joshi [79] was used to predict temperature distributions during the welding process. Most of the features incorporated by the authors were duplicated. The standard equation for heat conduction can be represented in both the temperature as well as the enthalpy forms as,

$$
\rho C_{p} \frac{\partial T}{\partial t}=\nabla \cdot(K \nabla T)+\dot{q}=\frac{\partial H}{\partial t}
$$

The model used three grids - fine, medium and coarse. The enthalpy form was used in the fine zone while the temperature form was used in the other two zones. The fine and medium grids move along with the torch while the coarse grid is stationary. The spatial terms were approximated with central differences to give a semi-discrete form of the heat conduction equation. The discretized form of the heat conduction equation in terms of temperature at an interior node in the 
medium zone is,

$$
T_{i, j, k}=\frac{\alpha}{x^{2}}\left(T_{i+1, j, k}+T_{i-1, j, k}+T_{i, j+1, k}+T_{i, j-1, k}+T_{i, j, k+1}+T_{i, j, k-1}-6 T_{i, j, k}\right)
$$

Here,

$$
\begin{aligned}
T_{i, j, k+1} & =\text { Temperature at node }(i, j, k+1) \\
\dot{T}_{i, j, k} & =\text { Rate of change of temperature at node }(i, j, k) \\
\rho & =\text { Density } \\
C_{p} & =\text { Specific Heat Capacity of the Solid } \\
t^{p} & =\text { Time } \\
\phi & =\text { Source Term } \\
x & =\text { Distance } \\
\alpha & =\text { Thermal Diffusivity }
\end{aligned}
$$

The semi-discrete equation shown above and the heat conduction equations in the other two zones were solved in time using a fourth order Runge-Kutta technique. The total heat generated by the arc was defined as the product of the arc voltage, arc current and an efficiency factor. This heat was distributed as a source term in the fine zone using an inverse-distance function within a volume specified as the weld pool. The source term was used while solving the enthalpy form of the heat conduction equation within the fine zone. Conductive, convective and radiative modes of heat transfer were assumed to take place at the surfaces of the plate being welded. This model is currently under development for possible application in predicting temperature distributions in the presence of perturbations.

The equations mentioned above were solved using software written in FORTRAN. This program was executed on a VAX 8540 computer. Interactive execution is at a rate of ten time steps per minute. The predicted surface thermal distributions have been plotted in the form of a surface in Figure 5 after 0.5 and 5 seconds of welding. These surfaces show the shape of the weld zone. The temperature distribution on the surface of the plate has also been plotted in the form of contour maps as seen in Figure 6 for 0.5 and 5 seconds of welding. These contour maps show that the isotherms are circular in shape initially and later become elliptic, as seen from experiment. Vertical sections of the weld plate at locations just below the arc were used to determine the shape of the weld pool and penetration depth, with prior knowledge of the melting point of the weld pool (Figure 7). The effect of a surface inclusion of size $1 \mathrm{~mm} X 1 \mathrm{~mm} X 1 \mathrm{~mm}$ on the temperature distributions is seen from the isothermal map in Figure 8 . The isotherms get elongated in the direction of welding and show a distinct distortion at the location of the inclusion. 

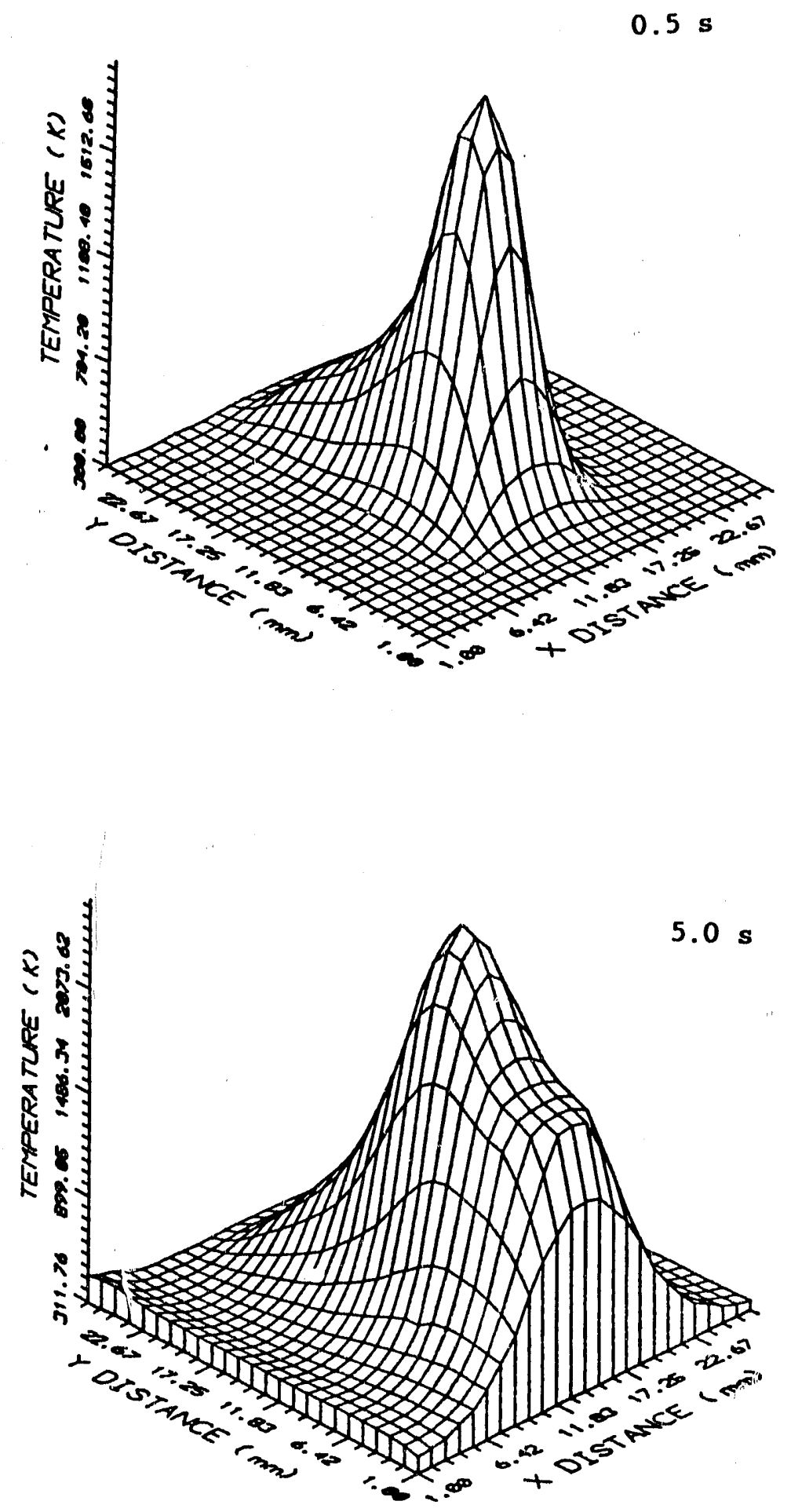

Figure 5. Computed Temperature Distributions - Surface Form 

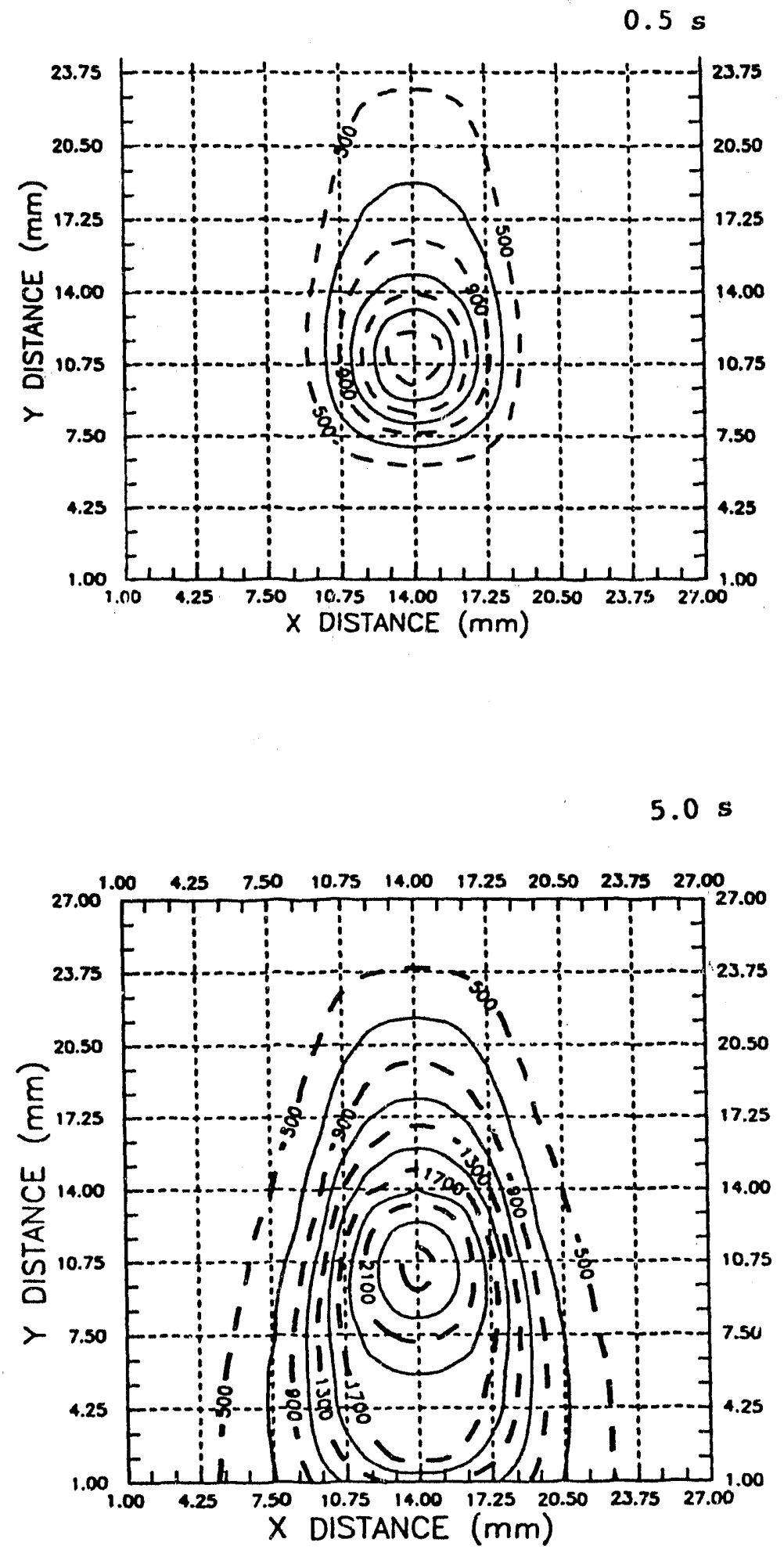

Figure 6. Computed Temperature Distributions - Isotherms 

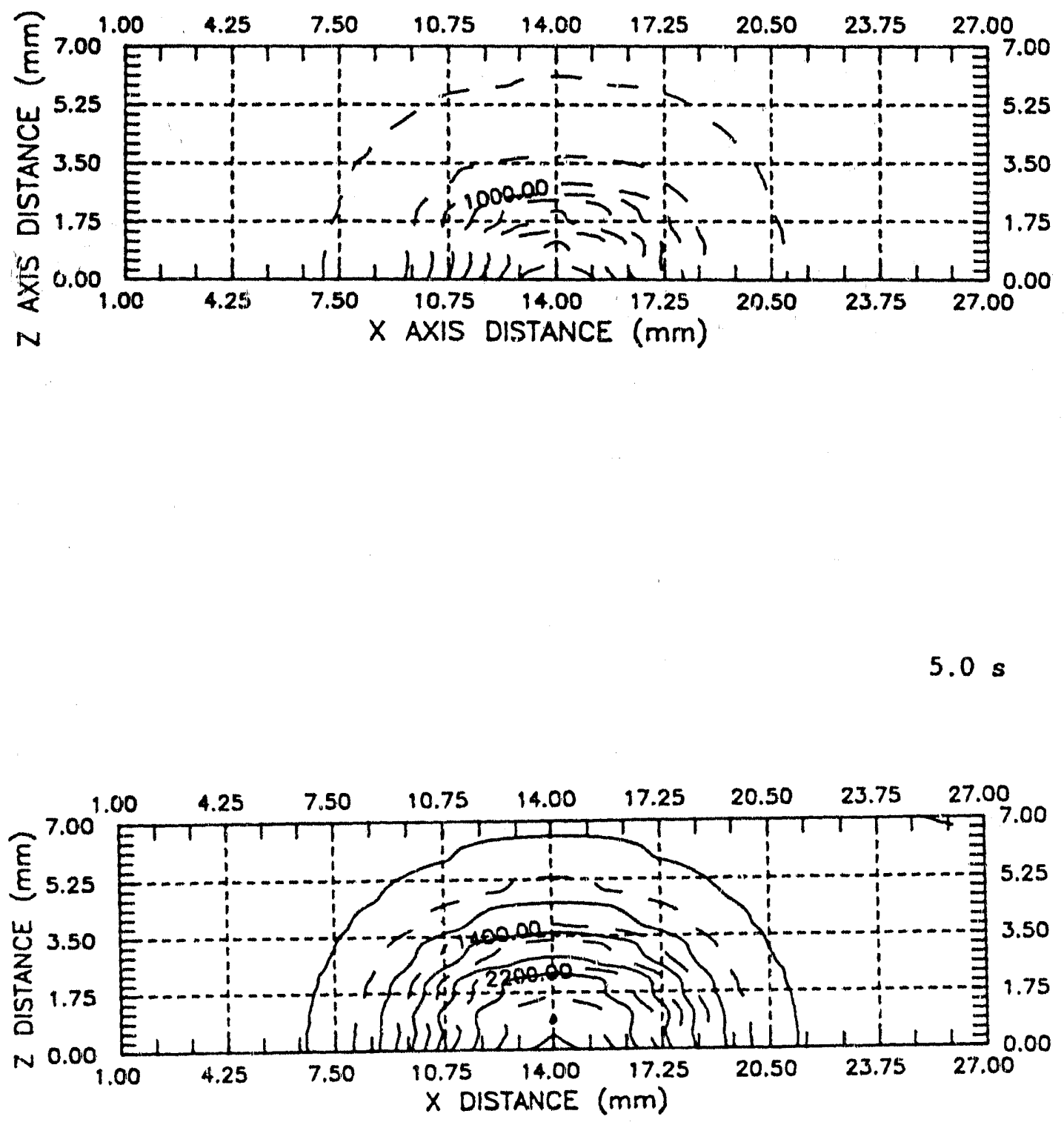

Figure 7. Computed Temperature Distributions at a Cross-section 

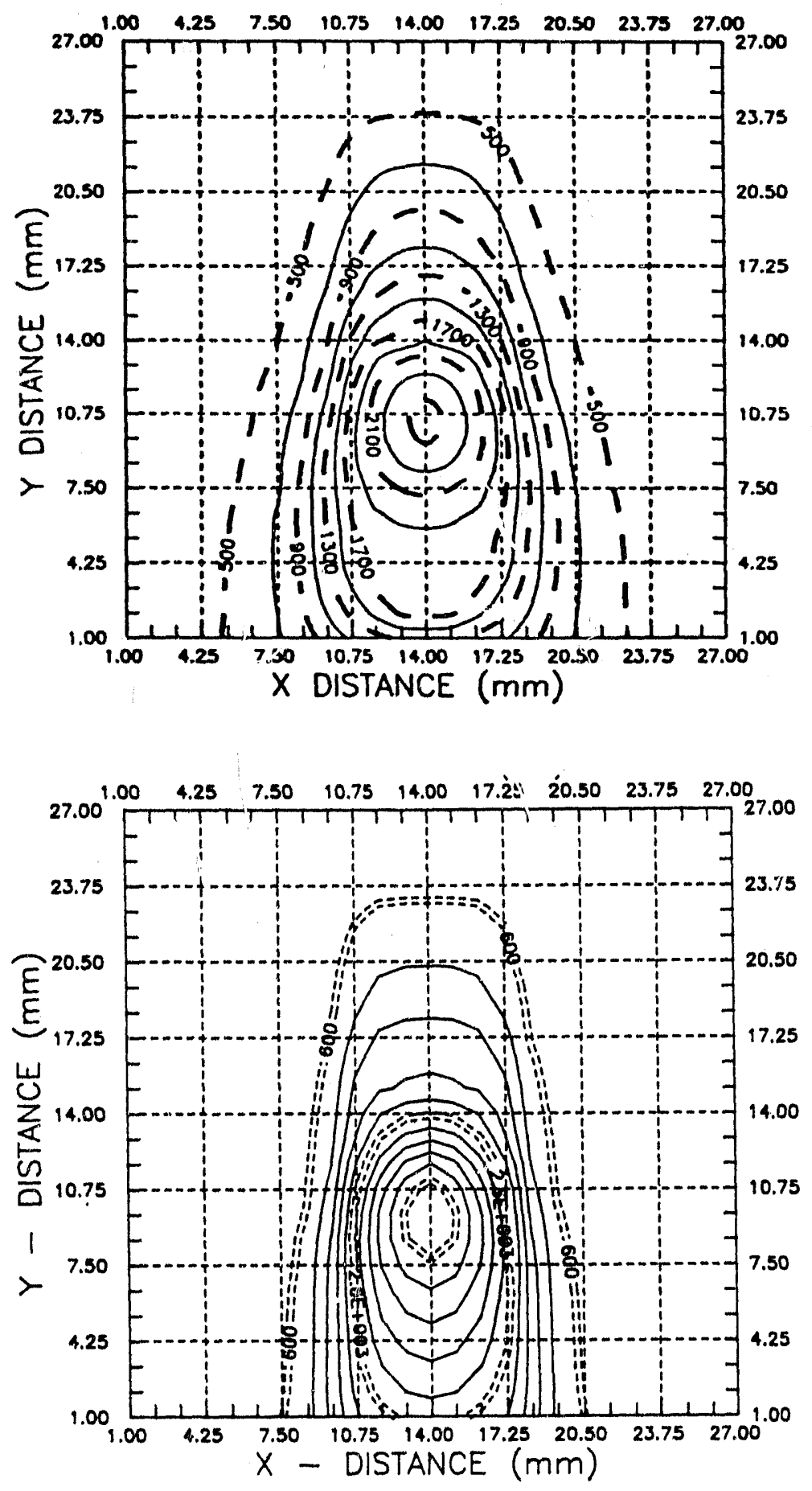

Figure 8. Effect of Surface Inclusion on Temperature Distribution 


\section{III.4 Shielding Gas Related Penetration Experiments}

The shielding gases used in the gas tungsten arc welding process play a very important role in heat conduction to the workpiece. Small changes in the shielding gas composition and/or flow rate can significantly alter the weld pool size.

The linescan scheme was used to identify changes in the weld puddle geometry, caused by changing the shielding gas composition. Argon and helium were used as shielding gases. Figure 9 shows the linescans across the weld pool. Broadening of heat intensity in the case of helium can be attributed to the fact that helium has a larger thermal conductivity relative to argon. A higher thermal conductivity enhances heat transfer transverse to the arc axis. To quantify these changes caused by the difference in thermal conductivity, temperature gradients were calculated across the weld puddle. Farlier experiments have shown that the solid-liquid metal interface is characterized by a change in intensity in a linescan [102]. Considering the solid-liquid metal interface, temperature gradients were computed as,

\section{Gradient $=$ Peak Intensity - Intensity at Interface Distance between Peak and Interface}

for each gas. Figure 10 shows a plot of temperature gradients versus the frame number. Experiments were conducted using different gas compositions ranging from $100 \%$ argon to $100 \%$ helium and vice versa. Destruct ive measurements we re used to calculate the change in bead width and penetration. Figure 11 shows that there is a linear relationship between percent penetration and the calculated temperative gradients for each shielding gas compusition. In order to demonstrate the accuracy of this method of identifying weld puddle changes, shielding gases were changed during a weld. A sudden drop in temperature gradients is observed with change in shielding gas from $100 \%$ argon to $100 \%$ helium (Figure 12). Efforts are currently underway to control weld bead geometry by changing current once the gases have been interchanged.

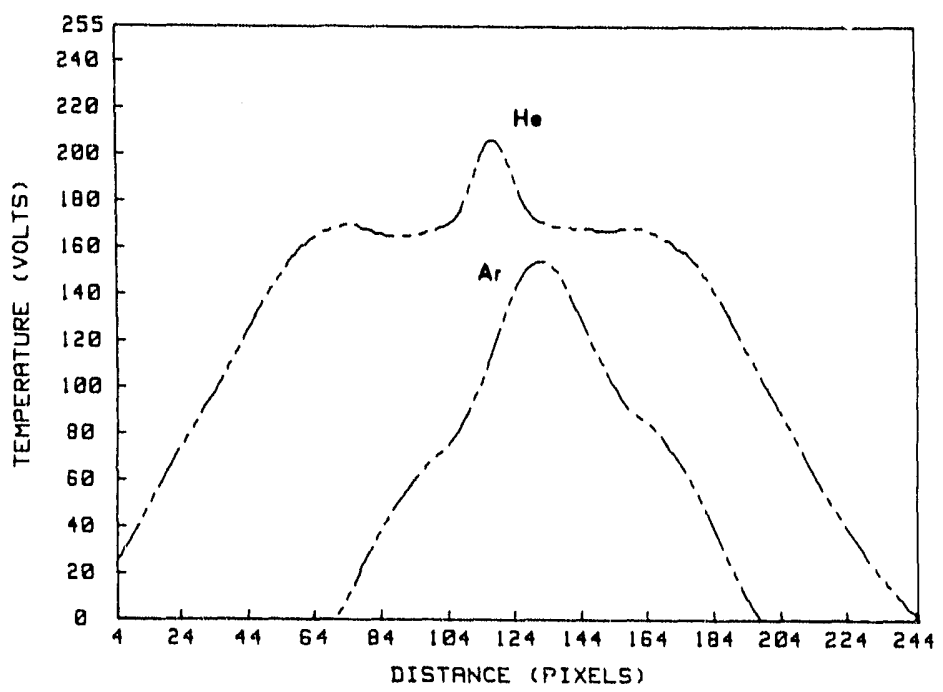

Figure 9. Linescans - Argon and Helium Shielding Gas 


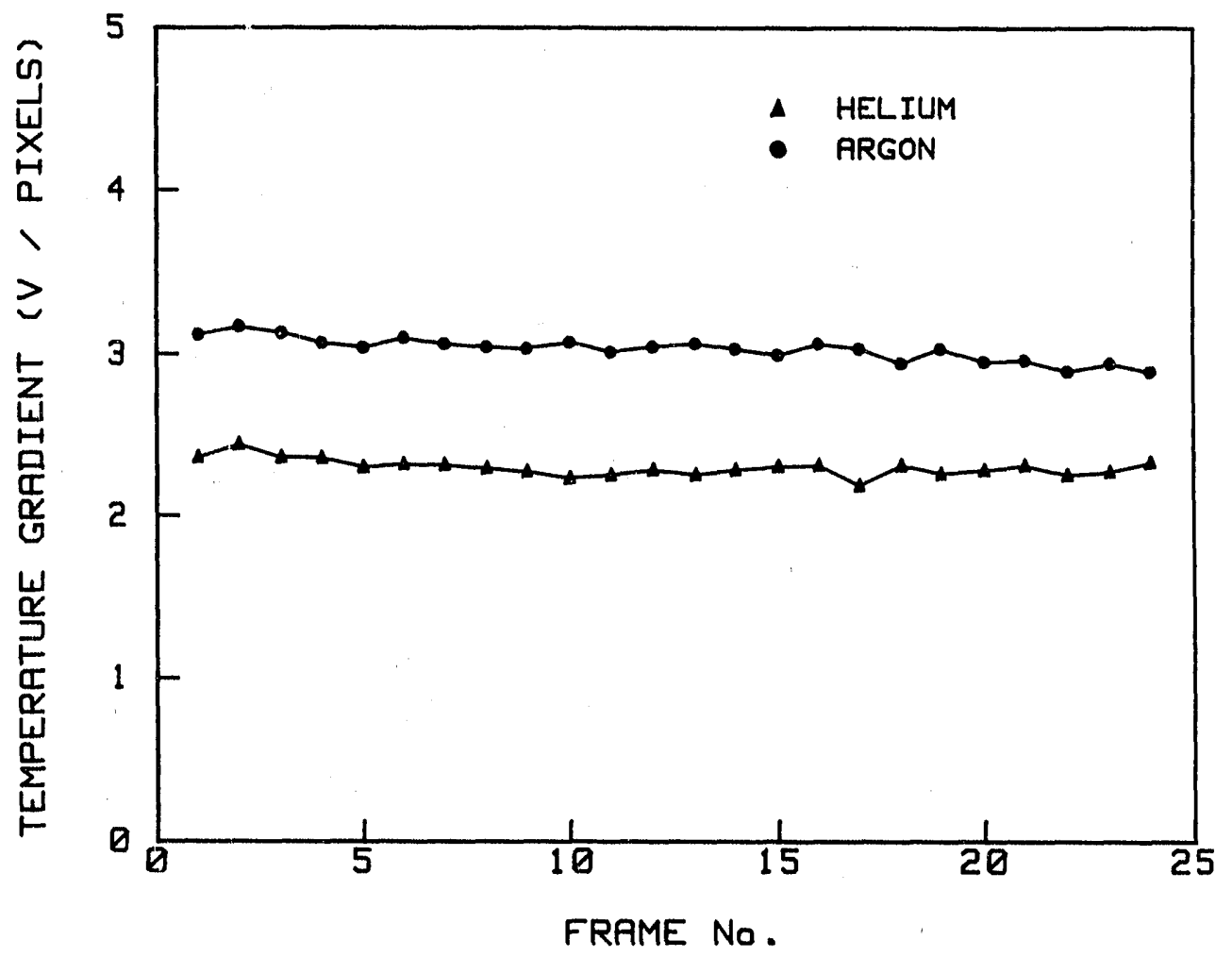

Figure 10. Temperature Gradient - Argon and Helium Shielding Gas

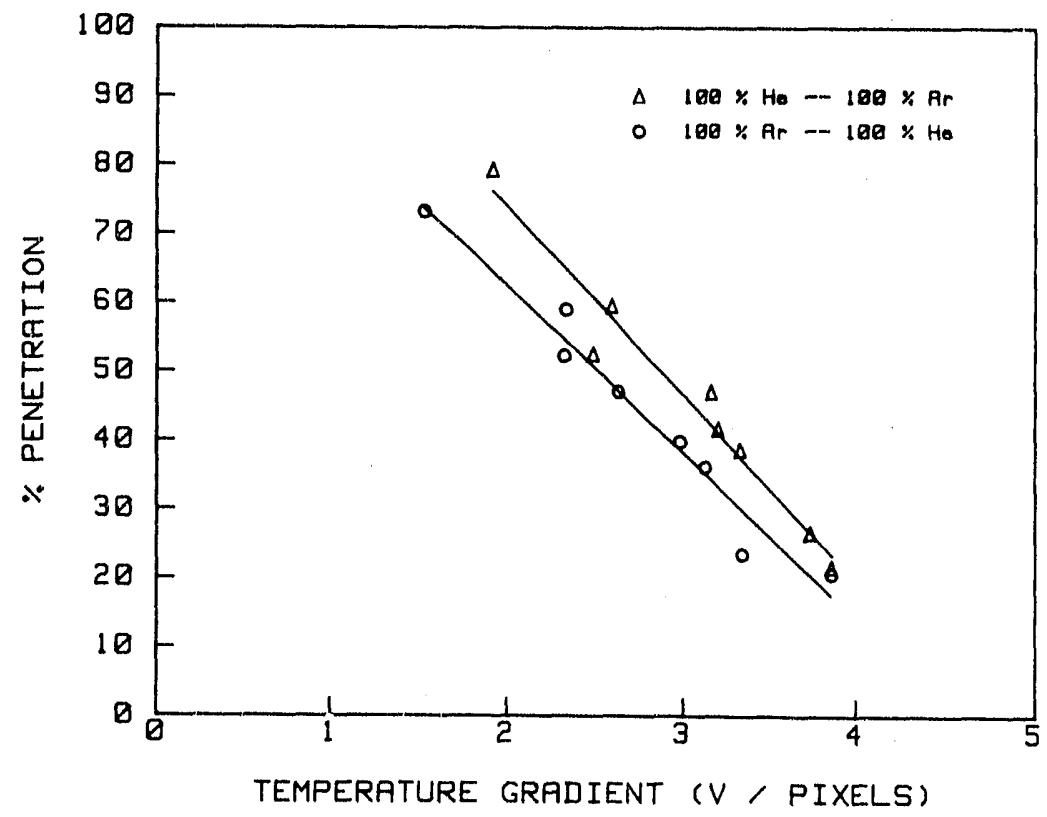

Figure 11. Penetration-Gradient Relation as a Function of Gas Composition 


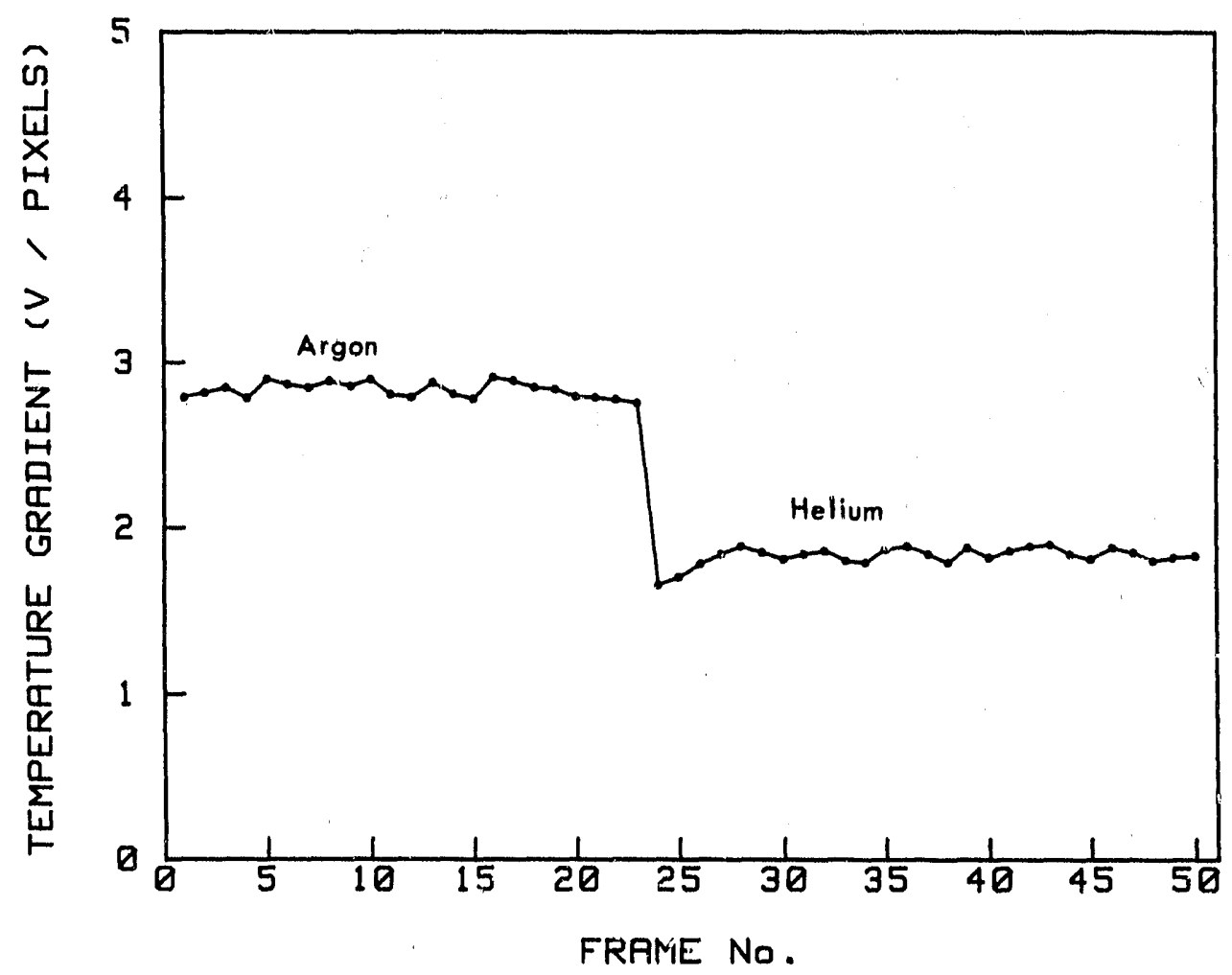

Figure 12. Effect of In-Process Shielding Gas Change

\section{III.5 Gradient Technique Experiments}

Different mathematical techniques have been investigated to determine the location of the solid-liquid metal interface. The gradient technique is the most promising.

As mentioned in the last annual report, the gradient technique was used to measure the bead width. This technique is based on the change in the temperature gradient at the solid-liquid metal interface. The calise for the change in the temperature gradient is the difference in the emissivity of the solid and liquid metals. As seen in Figure 13, each linescan shows three inflection points on each side of the line of symmetry A-B. At these inflection points, the slope of the line scan changes from an increasing type to a decreasing one or vice versa. The left hand side valley and the right hand side peak lie at locations corresponding to the second inflection point. The bead width was computed as the distance between the left hand side valley and the right hand side peak. Also, the solidified weld pool front was computed by locating the solid-liquid metal interface for regions ahead of the welding torch.

During the last year, the gradient technique was used to detect weld penetration changes resulting from step changes in thickness. Welds were 


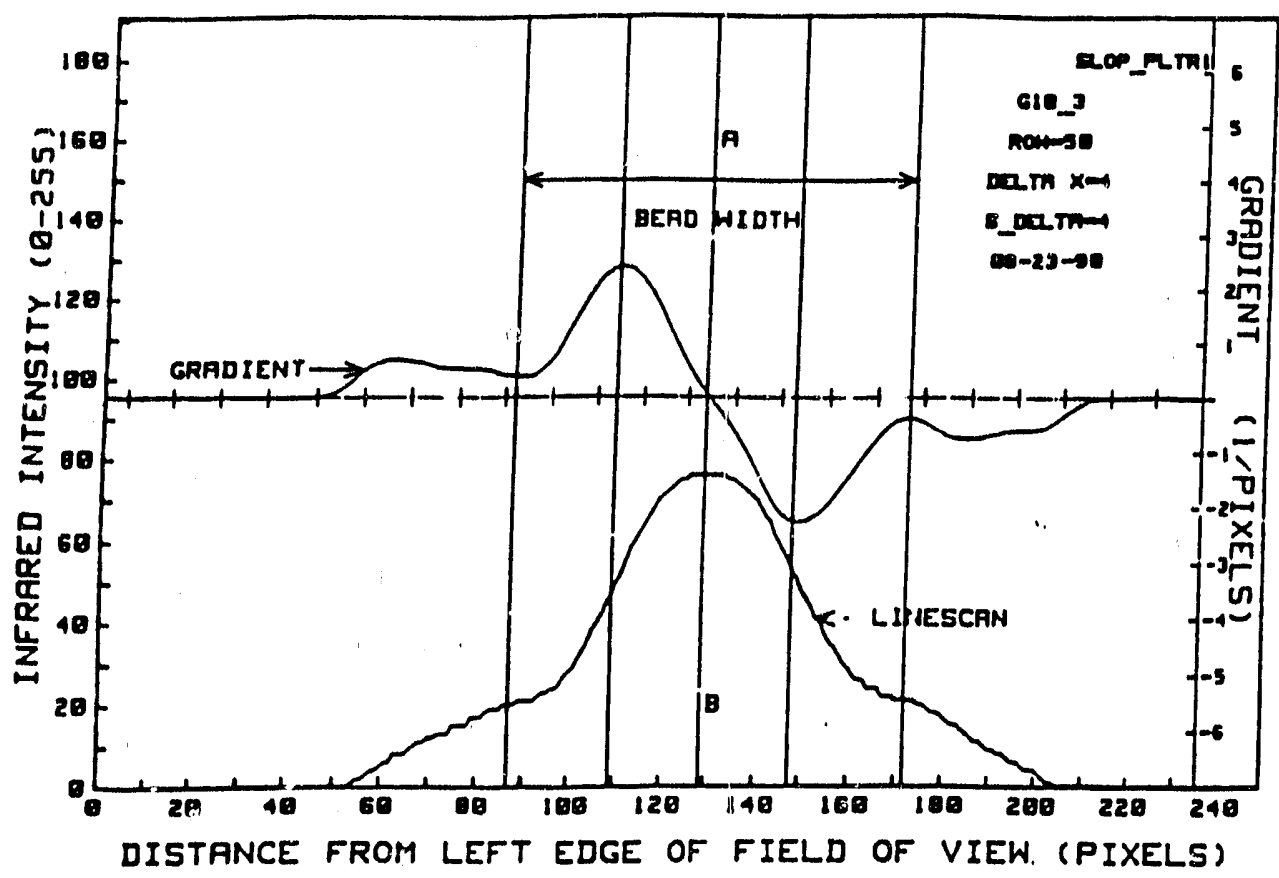

Figure 13. Gradient Technique

performed on steel plates with step changes in thickness. The steps had a dimension of $1 / 8$ " and 1/16". Post weld bead width measurements showed a region of gradual decrease in bead width in the transition region and a region of uniform bead width within each step.

Figure 14 shows the weld pool front computed from ten consecutive infrared data frames at one such step change ir thickness. As shown on the left hand side of the plot, tha cross-section of the steel plate changes from $6.35 \mathrm{~mm}(0.25 \mathrm{in})$ to $3.18 \mathrm{~mm}(0.125 \mathrm{in})$. The welding torch travels from top to bottom in the plot. The region shown in the plot corresponds to a torch travel distance of $5 \mathrm{~mm}$. The two inclined solid lines seen on the plot show the location of the actual edges of the solidified bead. As seen from the plot, the predicted weld pool front represents the actual solidified front. The bead width computed from the gradient technique is plotted against the bead width measured after the weld, at different locations in the same welding run (Figure 15). The linear relation indicates that the penetration detection technique is reliable.

\section{III.6 Minor Element Experiments}

Minor element concentration has been known to influence the convective flows in weld pools. Minor elements alter the surface tension coefficient of the 


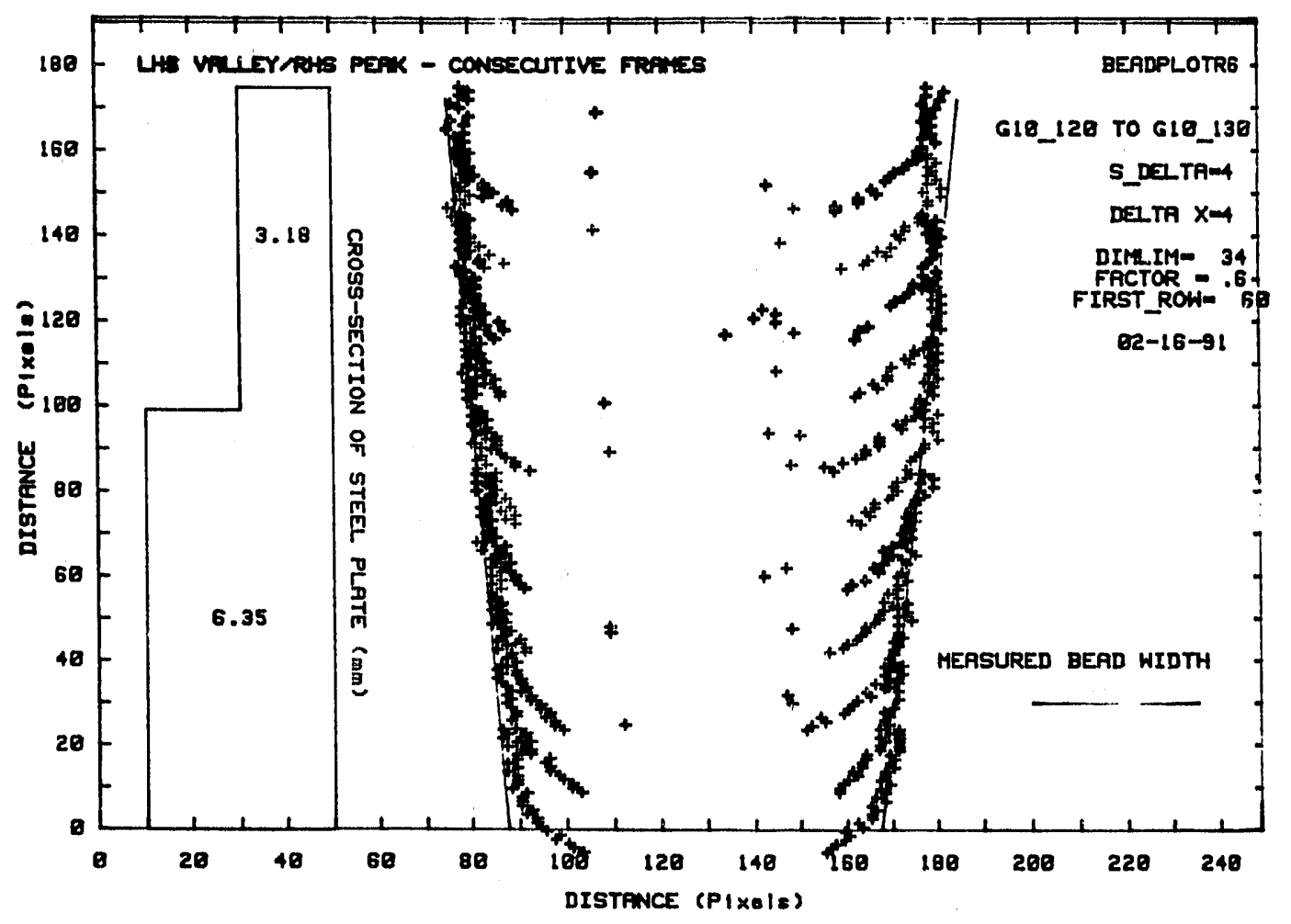

Figure 14. Computed Weld Pool Front for a Step Change in Thickness

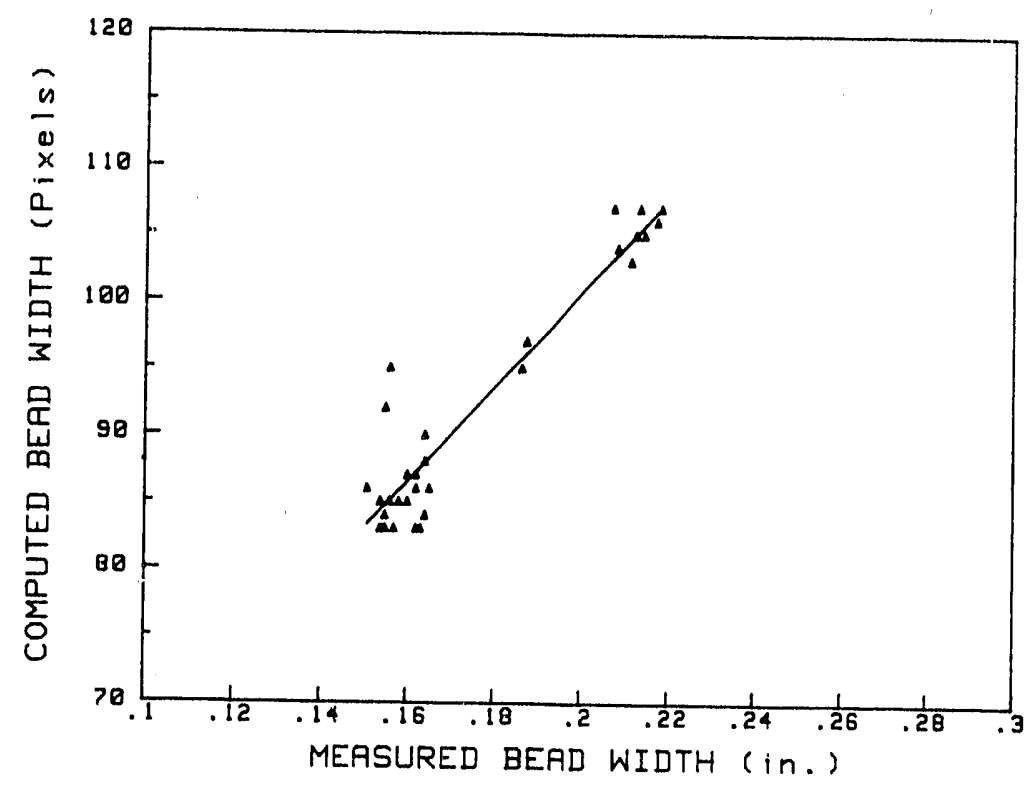

Figure 15. Comparison of Measured and Computed Bead Widths 
molten pool [73-76]. Sulfur, titanium dioxide and silicon have positive surface tension coefficients. These elements exhibit an increase in the surface tension of the weld pool with increase in temperature (Figure 16). Aluminum, oxygen and nitrogen as well as the base metal itself, have negative surface tension coefficients i.e., in the presence of these elements, the surface tension of the weld pool decreases with increase in temperature (Figure 16). In any weld pool, the surface temperature increases from the edge of the weld pool to the center. Thus, for a weld pool that experiences a sudden increase in sulfur content, there is an increase in surface tension from the edge to the center of the weld pool. Consequently, the convective flow changes from radially outward to radially inward and down to the bottom of the crater containing the weld pool. This results in a narrower, deeper weld pool (Figure 16) and hence increased depth of penetration and reduced bead width. On the other hand, an increase in the aluminum content leads to a change to a radially outward flow that travels along the outer edges of the weld pool to the bottom of the crater containing the melt. This produces a wider, shallower molten pool (Figure 16) and hence reduced penetration and increased bead width.

Penetration changes due to minor element concentration gradients were induced in two different ways - using arc melted high minor element content strips and by using minor element inserts. In both cases, the infrared data was analyzed to detect the influence of minor elements on penetration.

\subsubsection{Arc Melter Experiments:}

In order to alter the composition of the base metal, a method for precise control of the chemical composition was necessary. The arc melter was chosen because of its ability to produce small ingots (buttons) with close composition tolerances.

The arc melter (Electric Arc Button Remelt Furnace) was designed to produce solid buttons 1.25" in diameter and 0.25 " thick for alloy research. The instrument consists of eight primary components, i.e., base plate, de-staco clamp, lower water cooled body with the copper crucible, the upper body, the water cooled anode rod, handle grips and the anode (Figure 17).

The procedure for operation of the arc melter is simple - a DC power supply with a capacity of 400 to 600 Amps is connected to the two electrodes of the melter. A weighed amount (less than 50 grams) of the charge material is put into the crucible. The system is sealed and subjected to vacuum. Argon is used to flush out any remnant air. This procedure is repeated twice and eventually the system is operated under a positive argon pressure. An arc is struck between the anode and the cathode. This arc is maintained for about 50 seconds until the entire charge has melted. The power supply is then cut off and the melt is allowed to solidify into an ingot.

The argon atmosphere ensures that the button does not get oxidized. The violence of the arc creates agitation or stirring of the melt, thus producing a homogenous sample. Due to the short melt period ( 40 to 50 seconds), most elements undergo little or no volatilization. This is especially useful in 
designing alloys. The arc melter was used to produce low carbon steel samples containing different sulfur/aluminum contents. The desired and the spectroscopically measured sulfur/aluminum contents are shown in Table 2 .

Table 2. Composition of Arc Melted Buttons

\begin{tabular}{|c|c|c|c|c|c|c|c|c|c|}
\hline Sample No. & Desired ${ }_{C}$ & $\begin{array}{l}\text { posit } \\
\text { S }\end{array}$ & $\begin{array}{c}\text { ion (\%) } \\
\text { AT }\end{array}$ & $c^{M e}$ & $\begin{array}{l}\text { sured } \\
\text { Si }\end{array}$ & Comp & $\begin{array}{c}\text { ositi } \\
S\end{array}$ & $\begin{array}{c}\text { on }(\%) \\
\text { AT }\end{array}$ & W \\
\hline $\begin{array}{l}1 \\
2 \\
3 \\
4 \\
5\end{array}$ & $\begin{array}{l}.11 \\
.11 \\
.11 \\
.11 \\
.11\end{array}$ & $\begin{array}{l}.018 \\
.018 \\
.018 \\
.075 \\
.048\end{array}$ & $\begin{array}{l}.215 \\
.075\end{array}$ & $\begin{array}{l}.11 \\
.11 \\
.10 \\
.09 \\
.15\end{array}$ & $\begin{array}{l}-- \\
\cdots \\
-- \\
.01 \\
--\end{array}$ & $\begin{array}{c}.016 \\
\ldots \\
\cdots \\
\cdots \\
\ldots\end{array}$ & $\begin{array}{l}.018 \\
.018 \\
.018 \\
.077 \\
.042\end{array}$ & $\begin{array}{l}. \\
.208 \\
.073 \\
-\ldots \\
-\ldots\end{array}$ & $\begin{array}{l}.15 \\
-26 \\
.26 \\
-. .\end{array}$ \\
\hline
\end{tabular}

The solidified ingots were sand blasted and machined to remove any surface inhomogeneities. These ingots were then heated in a furnace to $1000^{\circ} \mathrm{C}$ for an hour. The ingots were hot rolled to a thickness of $1.5 \mathrm{~mm}$. These rolled strips were machined to a width of $6.35 \mathrm{~mm}(0.25 \mathrm{in})$. It must be mentioned here that the steel filings used in making the ingots were made from the same steel plates that the strips were finally fitted into.

In one set of experiments, the machined strips were fitted into slots cut on the surface of steel plates. The strips were spot welded at the ends to hold them in place (Figure 18). In another set of experiments, the strips were held vertically between two steel plates. The edges of the steel plates were milled to ensure a good fit. The two halves of the steel plate and the strip were then secured with the help of fasteners (Figure 18).
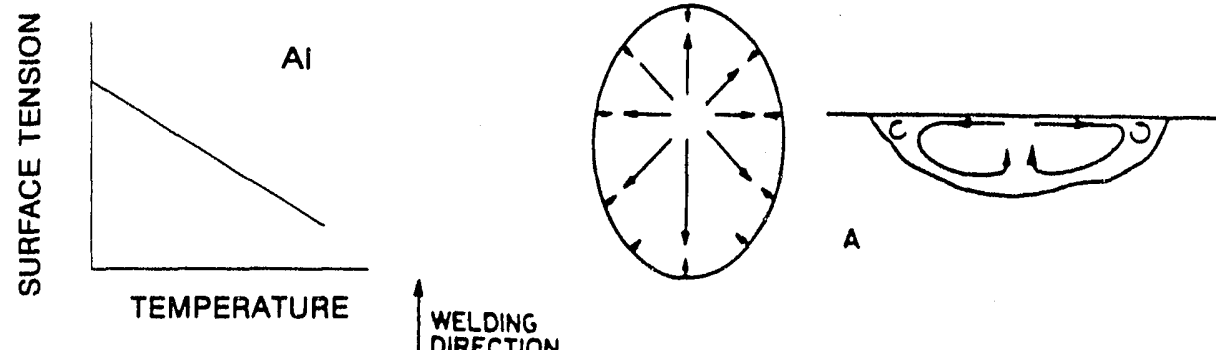

A
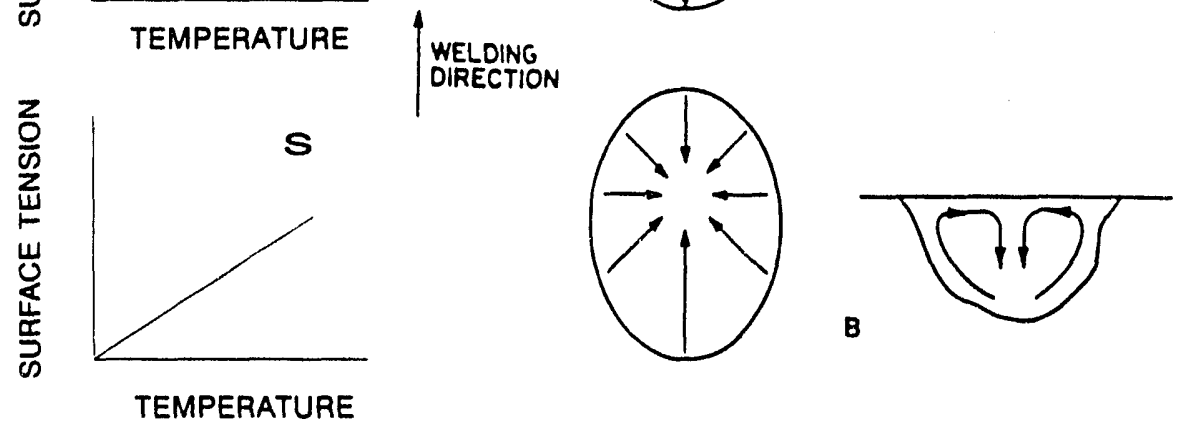

Figure 16. Minor Element Effects on Weld Pool Convective Flow 


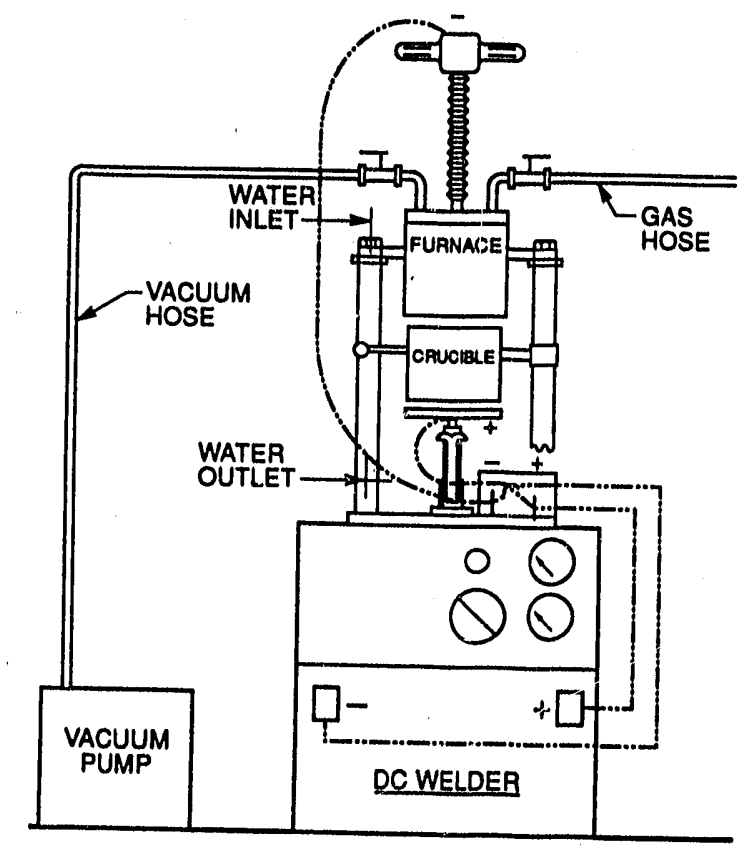

Figure 17. Schematic of Arc Melter

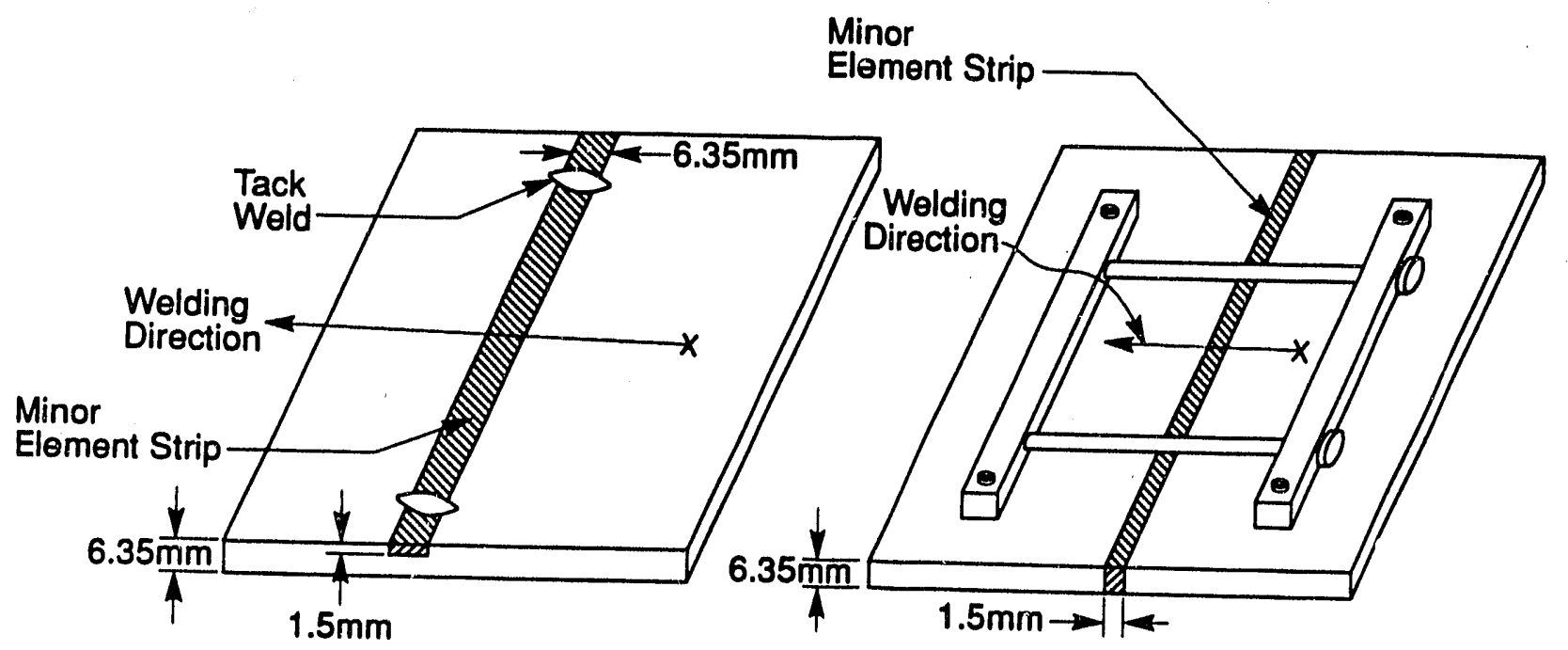

Figure 18. Minor Element Strip Fitup 


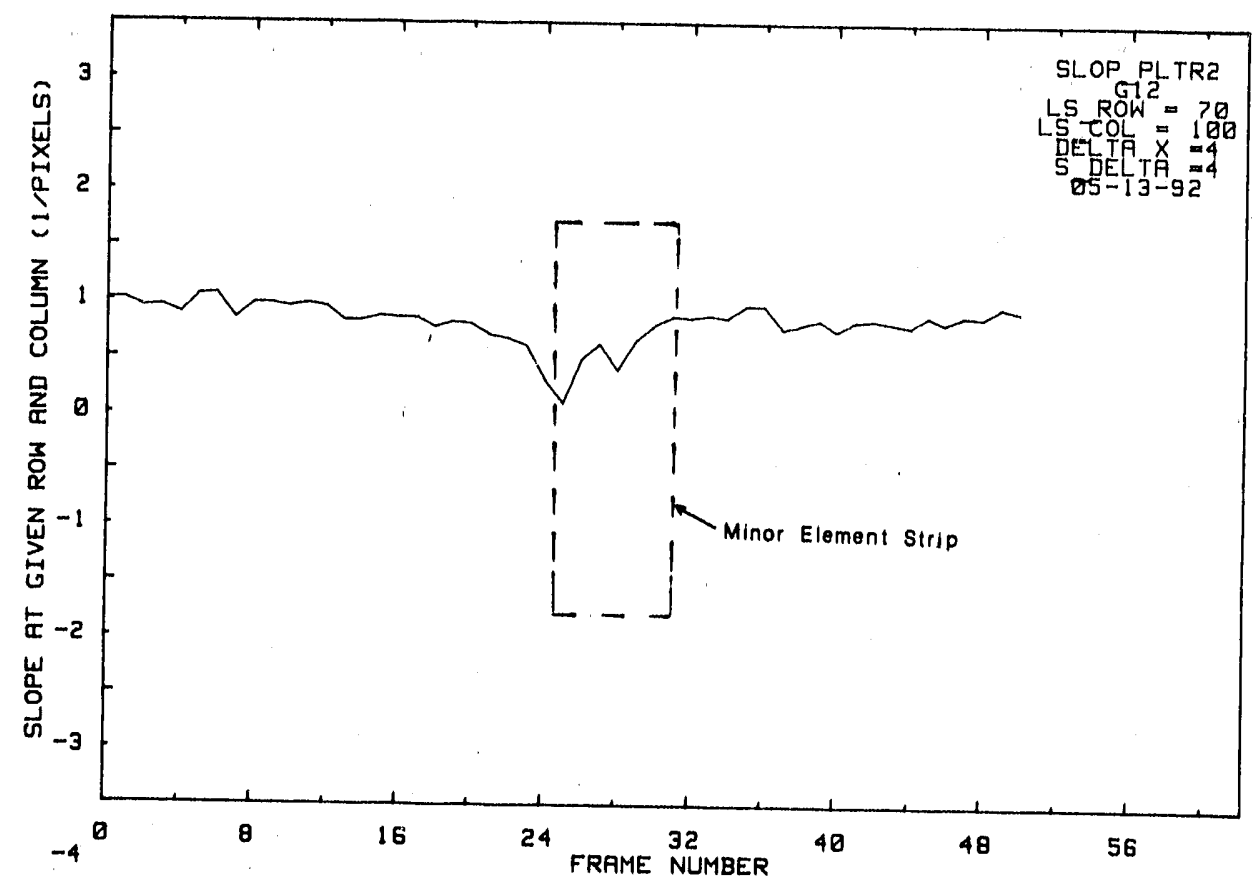

Figure 19. Temperature Gradient for Weld with Horizontal Minor Element Strip

\section{Arc Melter Results:}

When the strip was kept horizontally, infrared images acquired during the weld showed a characteristic change within the region containing the strip (Figure 19). However, the strip showed a tendency to warp and create a gap during the welding process. This resulted in the molten metal being sucked to other regions of the gap between the strip and the base metal. Also, voids were created in the weld itself. This was verified from a radiographic image of the welded plate. Therefore, vertical strips were used.

With the strip kept vertically, the welds did not show any voids. However, the infrared images failed to show a significant influence of the presence of the strip. Hence, an alcernate method using minor element inserts was used.

\section{III.6.2 Minor Element Insert Experiments:}

These experiments used two types of minor element inserts. One type contained elements with a positive surface tension coefficient (sulfur) while the other contained a negative surface tension coefficient (aluminum). On the base metal, $1 \mathrm{~mm}$ diameter holes were drilled and the minor element was force fitted. Aluminum wires and iron sulfide pieces were used as aluminum and sulfur inserts 
respectively. The location of the minor element inserts is shown in Figure 20.

For this set of experiments, $1 \mathrm{~mm}$ diametei holes were drilled into the base metal and either aluminum wires or iron sulfide pieces were force fitted into the holes. Welds were performed along a line passing through three minor element concentration sites. For each weld, one hundred frames of infrared data were acquired and analyzed. The gradient computed at points situated away from the vertical line of symmetry and within the weld pool was plotted for all the frames of data.

For the weld traversing the aluminum inserts, the gradient was found to decrease at the locations containing the inserts (Figure 21). This can be explained by considering what happens to the weld pool at these locations. Due to surface tension effects, aluminum increases the width of the weld pool. Given the same amount of heat input from the welding torch, a wider weld pool would mean a smaller temperature gradient across the weld pool.

For the weld passing through iron sulfide inserts, the gradient rose suddenly just before the inserts and then dropped sharply before returning to normal (Figure 22). Unlike aluminum, sulfur decreases the width of the weld pool and increases the depth. This increases the temperature gradient sharply. As soon as the effect of sulfur ceases, base motal surface tension effects come into play. These effects are similar to those of aluminum and hence result in a drop in gradient.

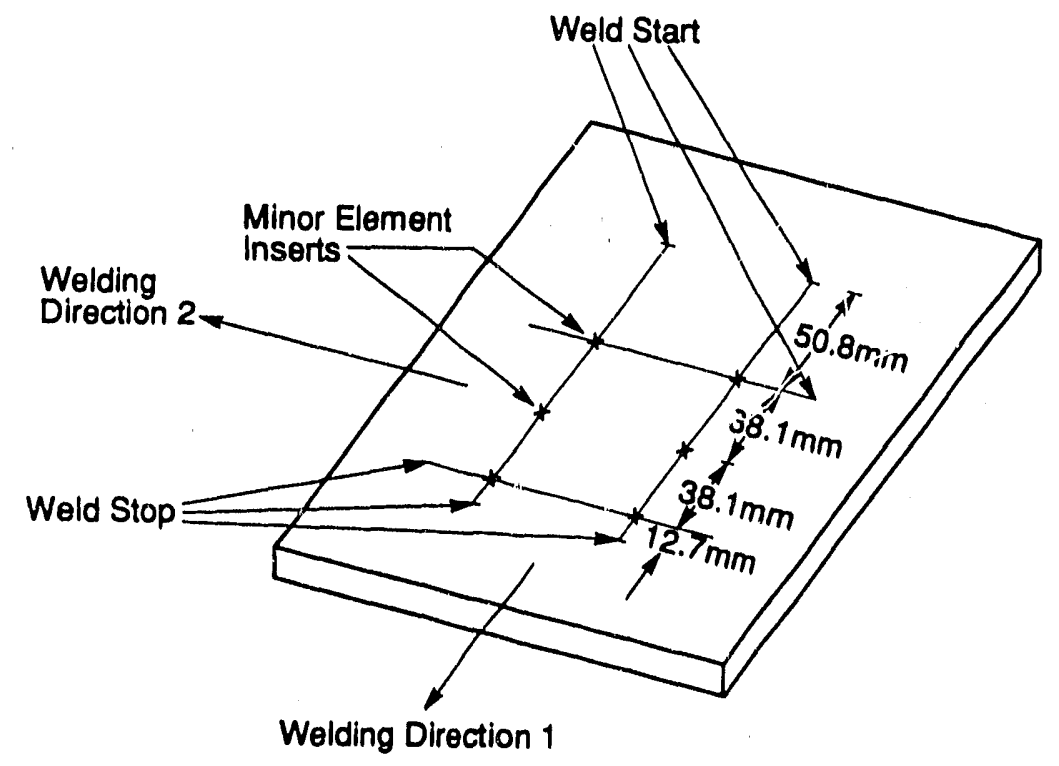

Figure 20. Steel Plates for Minor Element Insert Experiments 


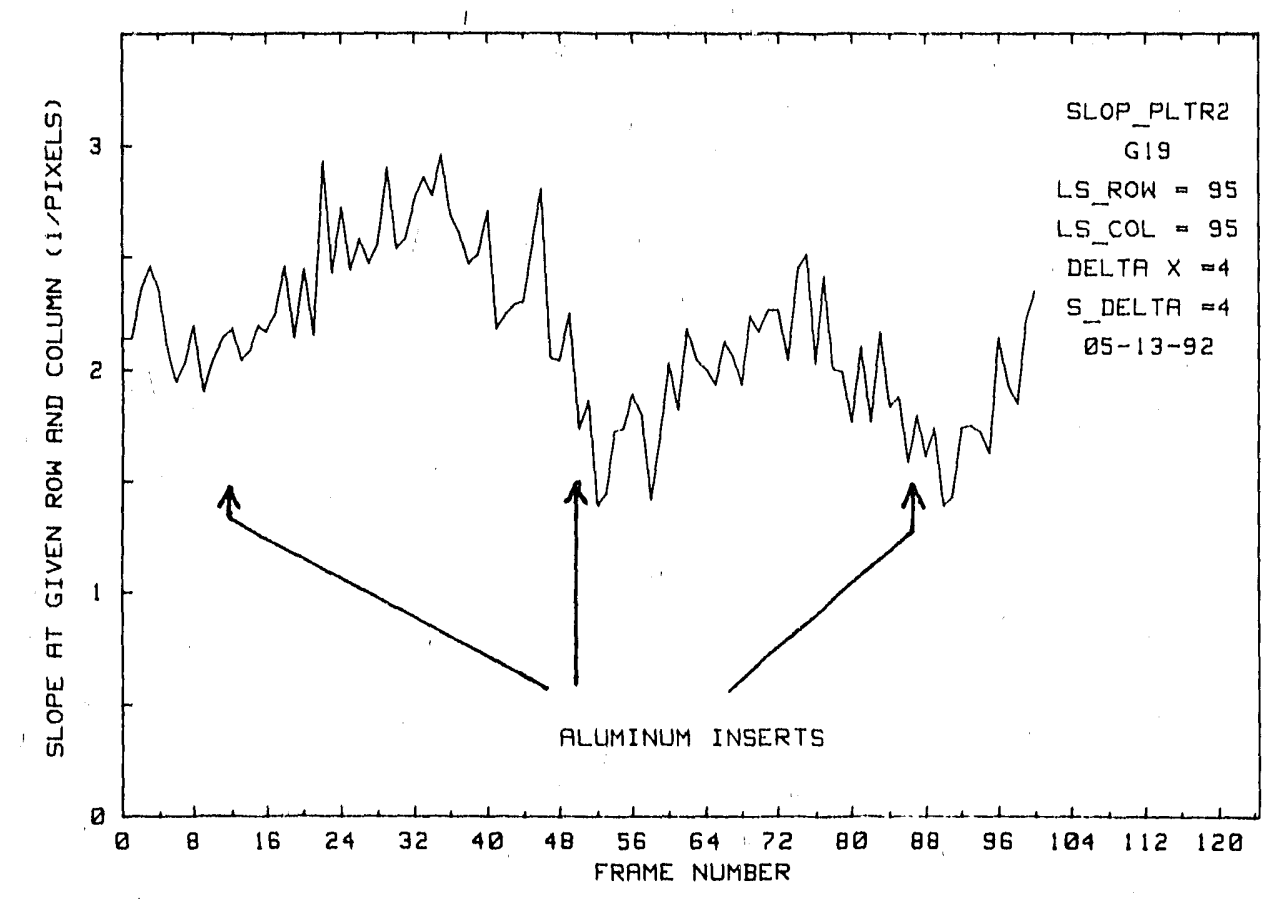

Figure 21. Temperature Gradient for Aluminum Insert Experiments

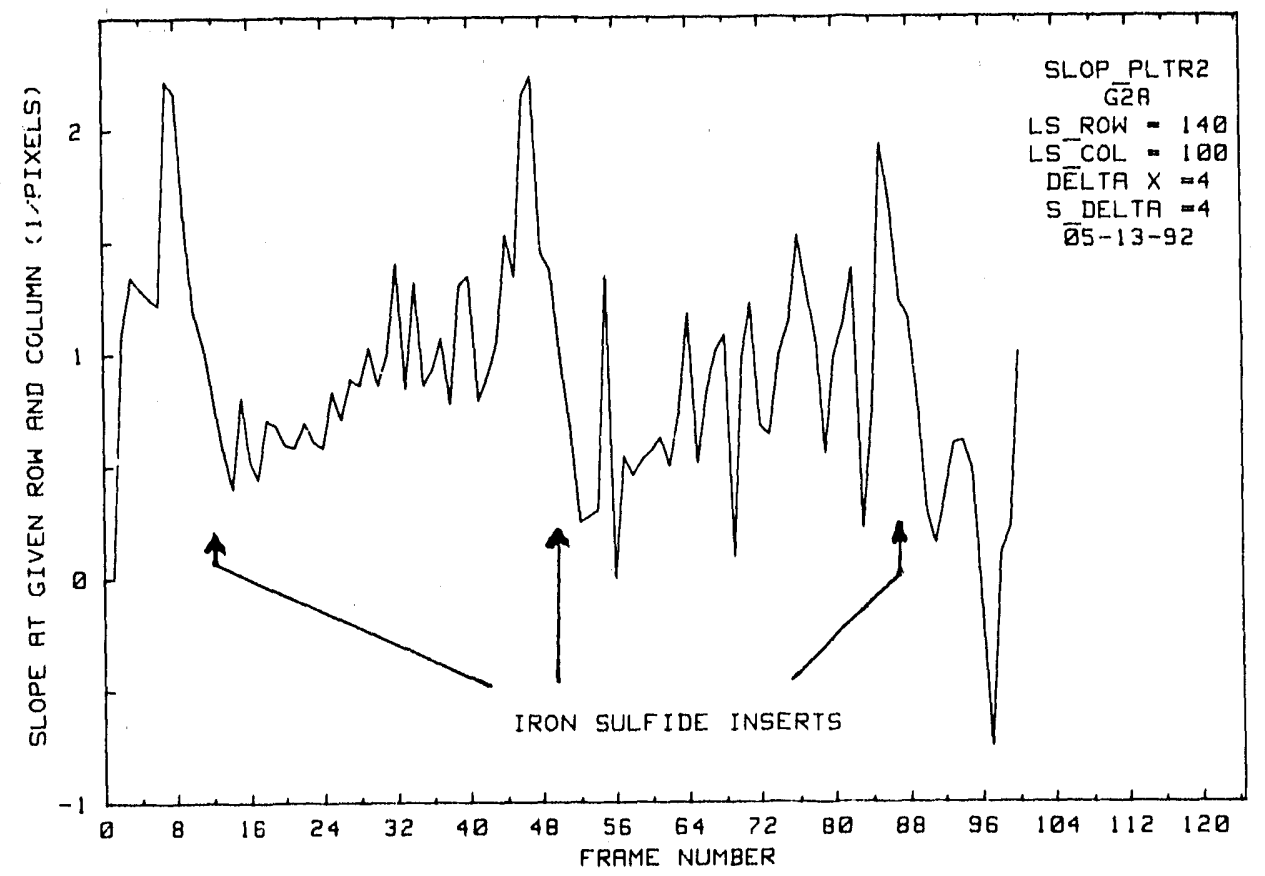

Figure 22. Temperature Gradient for Iron Sulfide Insert Experiments 


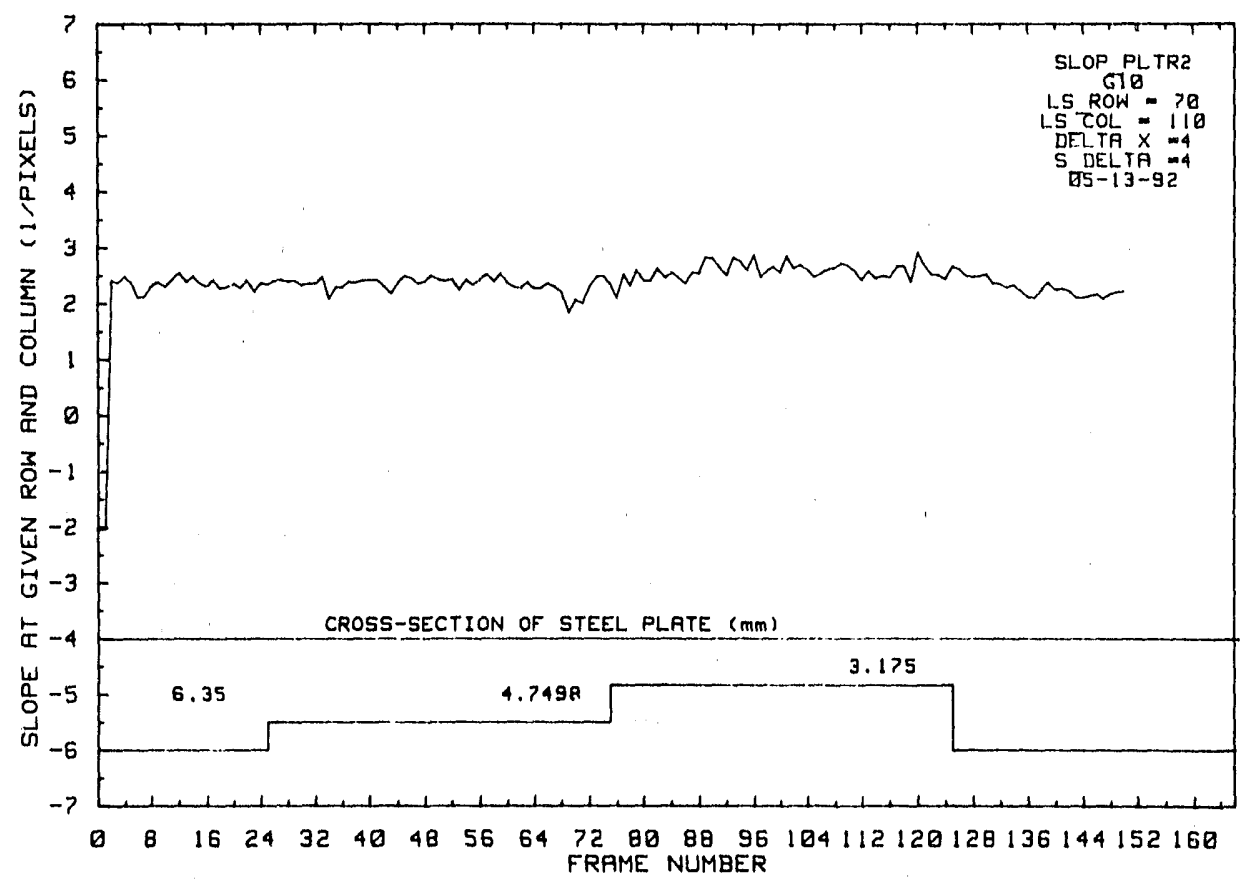

Figure 23. Temperature Gradient for Plate with Step Thickness Changes

It must be remembered that this type of change in the gradient at a point is unique to minor element effects and cannot be expected to result from other perturbations such as plate thickness changes. This was verified from a plot of the temperature gradient for a plate with step changes in thickness (Figure 23).

\section{III.7 Penetration Control based on Bead Width Control}

The computer routines for calculating the values of the peretration indicators were modified. This modification was necessary for reducing the time required to compute these signals. With prior knowledge of the approximate bead width for a given welding current, it was possible to reduce the number of columns and rows analyzed for determining the penetration indicators. The minimum time taken by the existing HP Model 320 computer to compute each penetration indicator is indicated in Table 3 . As seen from this table, gradient at a point has the least computation time while bead width along a line takes slightly longer. However, as seen in Section III,6.2, gradient at a point is best suited for detecting penetration changes resulting from minor element content changes. Bead width computed along a line transverse to the direction of torch motion was therefore used as an error signal in the control software. 
The strategy involved monitoring bead width variations with time. The percent change in bead width is converted into the amount of rotation of the remote current control transformer that is required to restore the bead width to its original value. After the current supplied by the transformer has been corrected to the new value, the bead width is again monitored and the process is repeated. The bead width variation for a given run and the corresponding changes in the remote transformer reading and welding current when using this software are shown in Figure 24.

Table 3. Time Constants

\begin{tabular}{|c|c|c|c|}
\hline Parameter & $\begin{array}{l}\text { Analyzed } \\
1 \text { Line } 1\end{array}$ & $\begin{array}{l}\text { for } \\
\text { Frame }\end{array}$ & Computation Time \\
\hline $\begin{array}{l}\text { Fitted ETlipse } \\
\text { Bead Width } \\
\text { Thermal Volume } \\
\text { Gradient at a Point }\end{array}$ & $\begin{array}{l}x \\
x\end{array}$ & $\begin{array}{l}x \\
x\end{array}$ & $\begin{array}{l}4 \text { mins } \\
.5 \mathrm{sec} \\
1 \mathrm{~min} \\
.09 \mathrm{sec}\end{array}$ \\
\hline
\end{tabular}

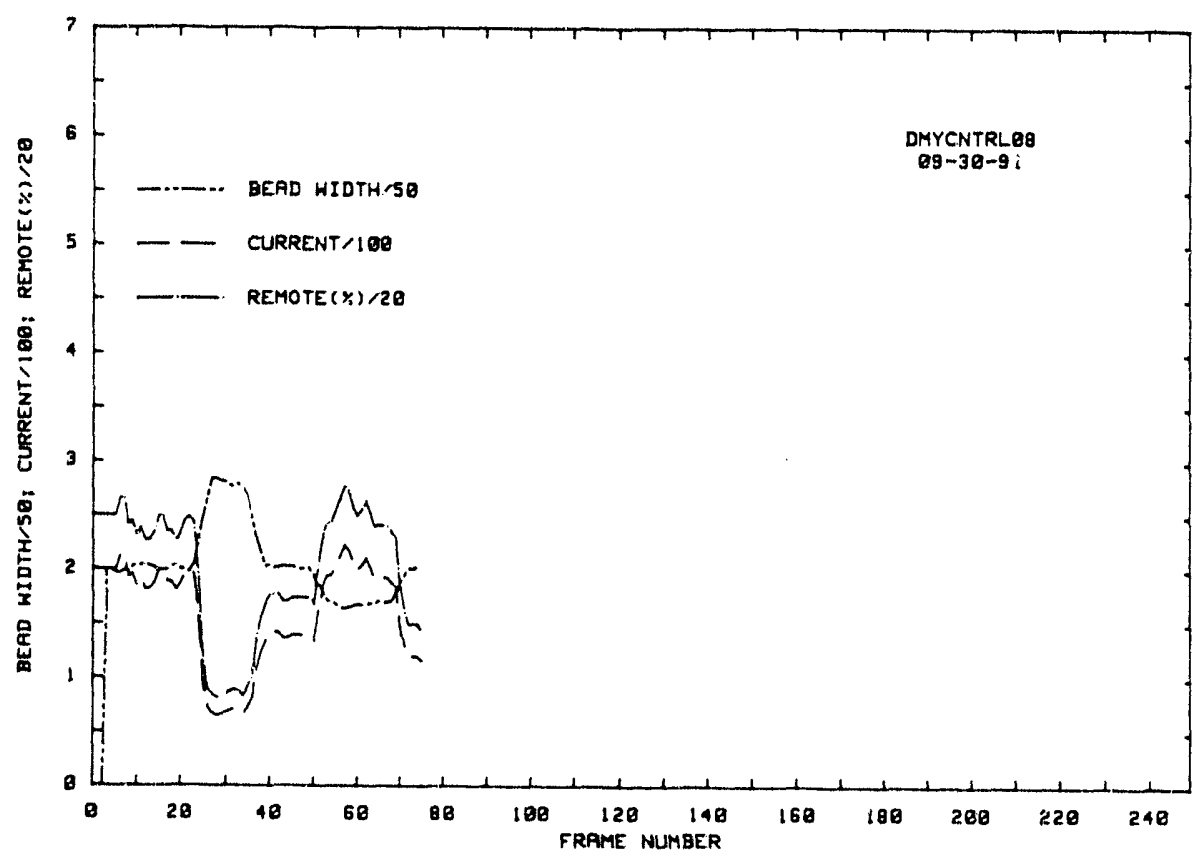

Figure 24. Simulated Weld Penetration Control 


\section{III.8 Correction of Initial zoint offset}

Efforts were concentrated on improving the ability of the system to detect and manage initial offsets of the weld from the joint. These offsets result from variations in the fixturing and positioning accuracy of the robot. Experiments were conducted to determine and correct such joint-torch offsets. A method is already in place to detect real-time joint-torch offsets in square butt weld joints [102]. A brief description of the existing method is presented below.

When the position of the joint and the torch do not coincide, the heat input by the arc is distributed unequally to the plates being joined. The amount of heat distributed in the plate towards which the torch is offset is greater than that to the plate farther away from the torch. The difference in heat distribution is caused by the thermal contact resistance of the joint. The effects of such unequal heat distribution were observed in the temperature distributions measured by the scanner. Symmetry of the temperature distribution was found to depend on the joint-torch offsets. When the torch and joint positions coincide, symmetric temperature distributions were observed ( Figure 25a). Asymmetric temperature distributions were produced when the torch is offset from the joint center (Figure 25b). In order to measure the joint-torch offset, the asymmetry in the observed temperature distribution was quantified. This was accomplished by comparing the half sizes or radii of selected isotherms (regions of equal temperatures) about the position of the torch. For instance, in an asymmetric temperature distribution, the left and right radius of the isotherm are unequal. The difference between the radii is directly proportional to the joint-torch offset. This technique was found to predict varying jointtorch offsets reliably [102].

The technique described above was used to correct initial joint-torch offsets produced by low tolerance levels in part fixturing techniques. These offsets were intentionally induced in the feedback control experiments by placing the torch away from the joint. Ten control runs were performed to study realtime correction of $2 \mathrm{~mm}$ joint-torch offset. In each control run, the offset was detected using the radii comparison technique. The detected offset was then corrected by altering the position of the torch. This corrective action involves two closely related sub-tasks: 1) the placement of the torch on the joint and 2) re-alignment of the scanning camera. The torch position is changed by varying the voltage vector and/or time period of the voltage applied to the $x$ and $y$ motor. A change in voltage vector alters the direction of torch motion and thus necessitates a camera re-alignment step. In order to minimize the number of scanner re-alignment steps, the voltage vector was held constant while varying the time period of the voltage pulse. Using this control strategy, a proportional controller was able to correct a torch-joint offset in real-time. The improved performance of the system is shown in Figure 26.

\section{III.9 Joint Gap Determination}

Tracking of joints with a finite size gap was also investigated. In the experiments conducted, gaps were intentionaliy induced in square butt weld joints. The edges of the plates to be welded were machined such that a gap was produced at the joint. Gap sizes ranging from 0.508-1.016 mm (0.02-0.04 in) were 
investigated. In a single experimental run, $228.6 \mathrm{~mm}$ ( 9 in) were welded. During the entire run, the joint regions ahead of the weld pool were scanned 50 times. In a single scan, infrared intensity distribution of a line transverse to the joint was measured. Welding process conditions used are listed below,

Table 4. Welding Conditions for Joint Gap Determination

1. Current

2. Voltage

3. Shielding Gas

4. Welding Speed
75 Amperes

18 Volts

Argon, $40 \mathrm{cfh}$

$2.667 \mathrm{~mm} / \mathrm{sec}$

Infrared intensity distribution of a line transverse to the joint is shown in Figure 27. A characteristic dip in the intensity profile was found to coincide with the position of the joint. This local minimum at the gap was produced as the infrared intensity emanating from the gap is lower than the intensity from the edges of the plate. The drop in infrared intensity is also prominently seen in the first derivative (slope) of the intensity profile, Figure 28. Now the gap can be characterized by three changes in sign of the slope or

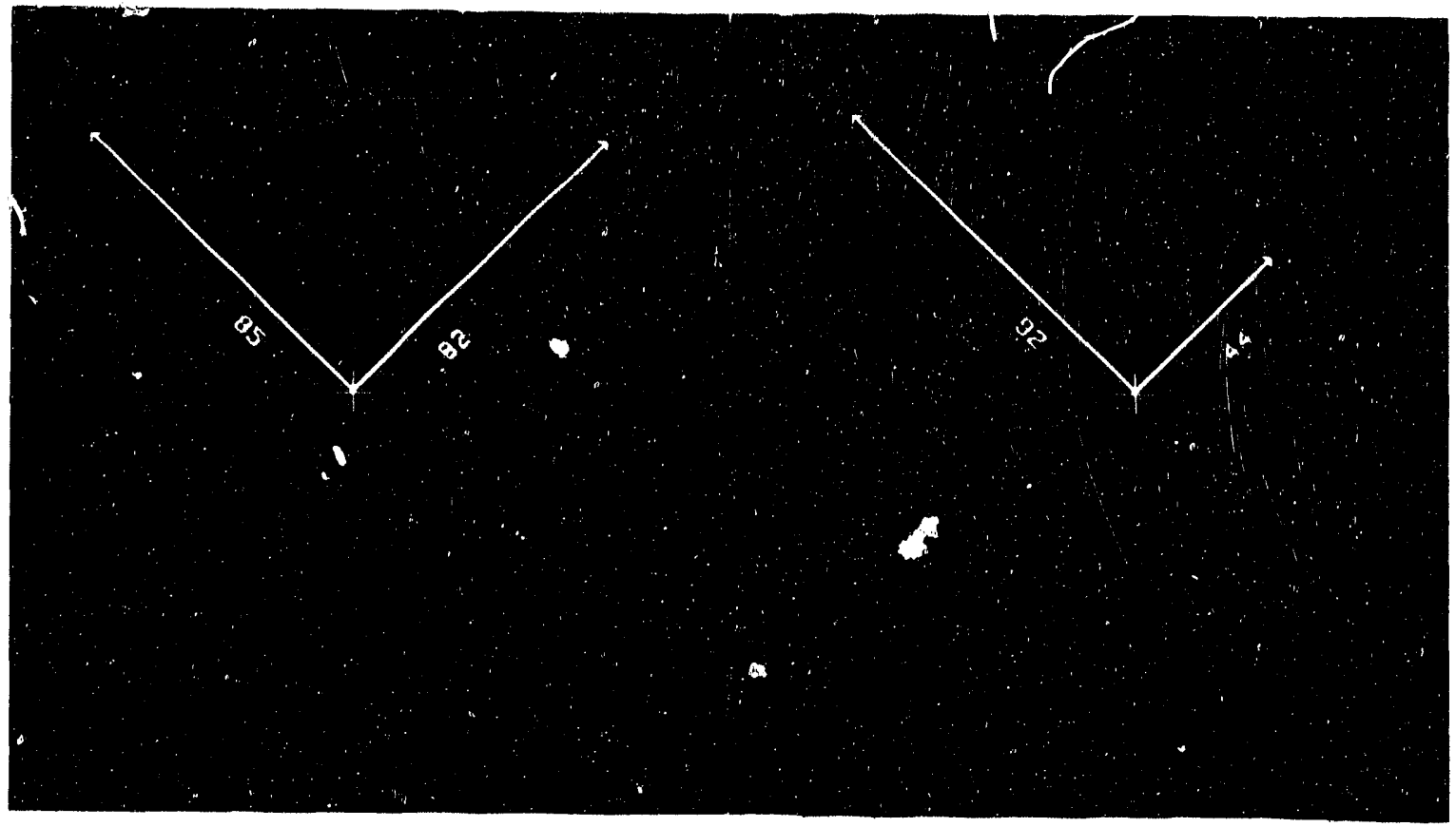

Figure 25. On-seam and Off-Seam Isothermal Distributions 


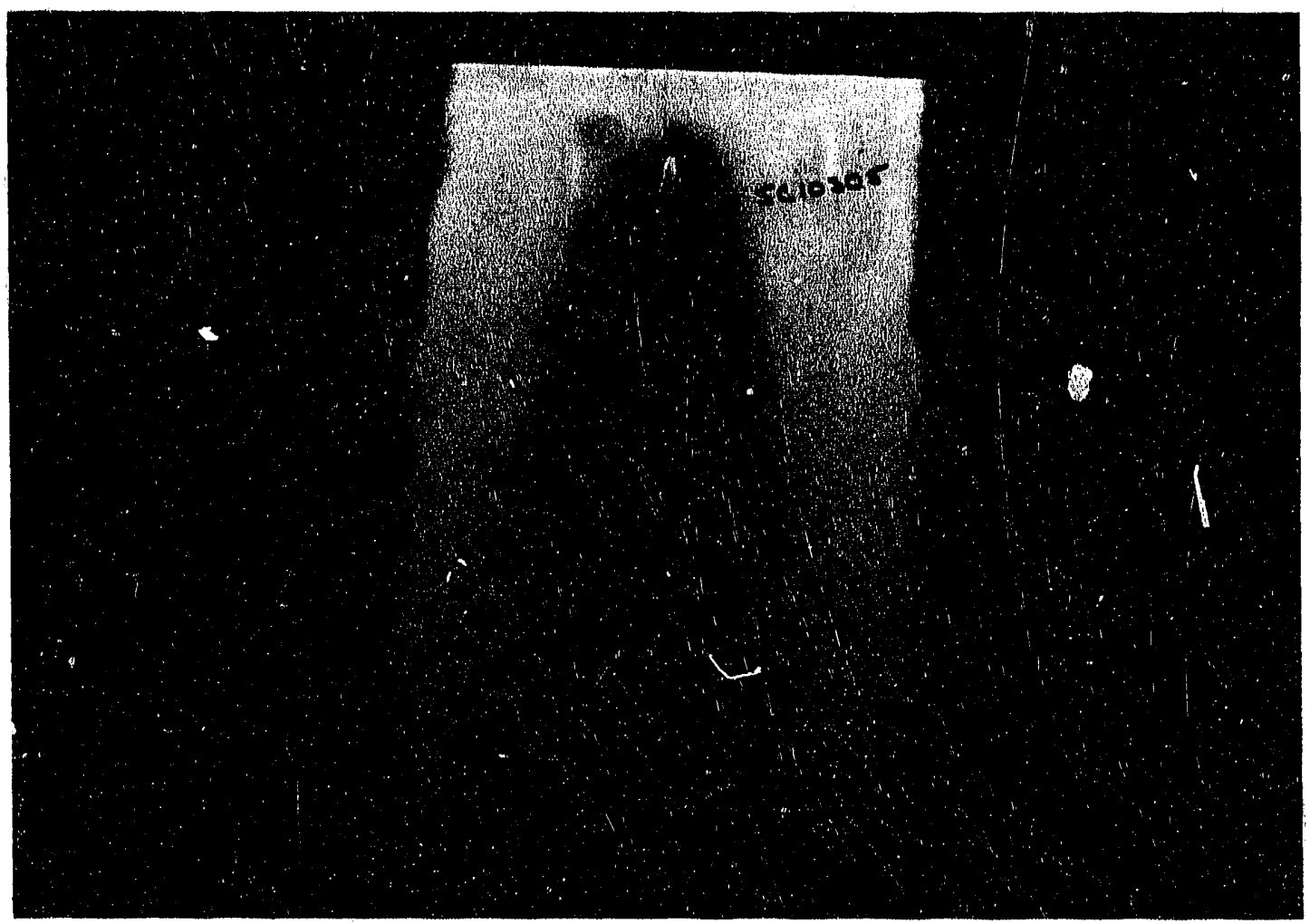

Figure 26. On-line correction of Initial Weld-Joint Offset

three zero derivatives. The gap center corresponds to the second change in sign of the slope. The size of the gap is proportional to the distance between the first and third changes in sign of the slope. The proportionality constant is directly related to the magnification factor of the scanner.

In Figure 29, the predicted gap size is plotted as a function of frame number. The frame number represents the time at which the joint was scanned. From each frame, one line of data was acquired and used in the control routine. The number of lines acquired was limited to 50 in order to reduce the overali data analysis time. To give an idea about the large volume of data that can be generated, the total number of lines that can be acquired in a $228.6 \mathrm{~mm}(9 \mathrm{ln})$ weld run is computed below,

$$
\begin{aligned}
& \text { Number of lines }=\text { Welding time * Data acquisition speed } \\
& =(228.6 / 2.667) * 30 * 192=493,714 \text { (1 ines) } \\
& \text { 1. Welding time = Weld length }(\mathrm{mm}) / \text { Speed (mm per sec) } \\
& =228.6 / 2.667 \text { (seconds) } \\
& \text { 2. Data Acquisition Speed }=\text { (Frames per sec)*(Lines per frame) } \\
& =30 * 192 \text { ( } 1 \text { ines per second) }
\end{aligned}
$$


The predicted gap size is expressed in pixel units. This can be converted into units of length $(\mathrm{mm})$ using the magnification factor, 9 pixels $/ \mathrm{mm}$. In Figure 29 , predicted values for three gap sizes $0.508 \mathrm{~mm}(0.02 \mathrm{in}), 0.762 \mathrm{~mm}(0.03 \mathrm{in})$ and $1.016 \mathrm{~mm}(0.040 \mathrm{in})$ have been compared. With increase in gap size, the predicted gap size also increases. In all the three cases, the predicted gap size decreases with increase in time. During the welding process, the molten metal contracts as it solidifies. This contraction draws the edges of the plates ahead of the solidifying metal, closer together and thus causes a decrease in the machined gap size. The above phenomenon was also visually observed. These results show that the characteristics of joint gaps can be determined using changes in the infrared intensity distributions. The developed techniques were used to identify the position of the joint and automatically track it in curved joint contours. The performance of the technique is shown in Figure 30 .

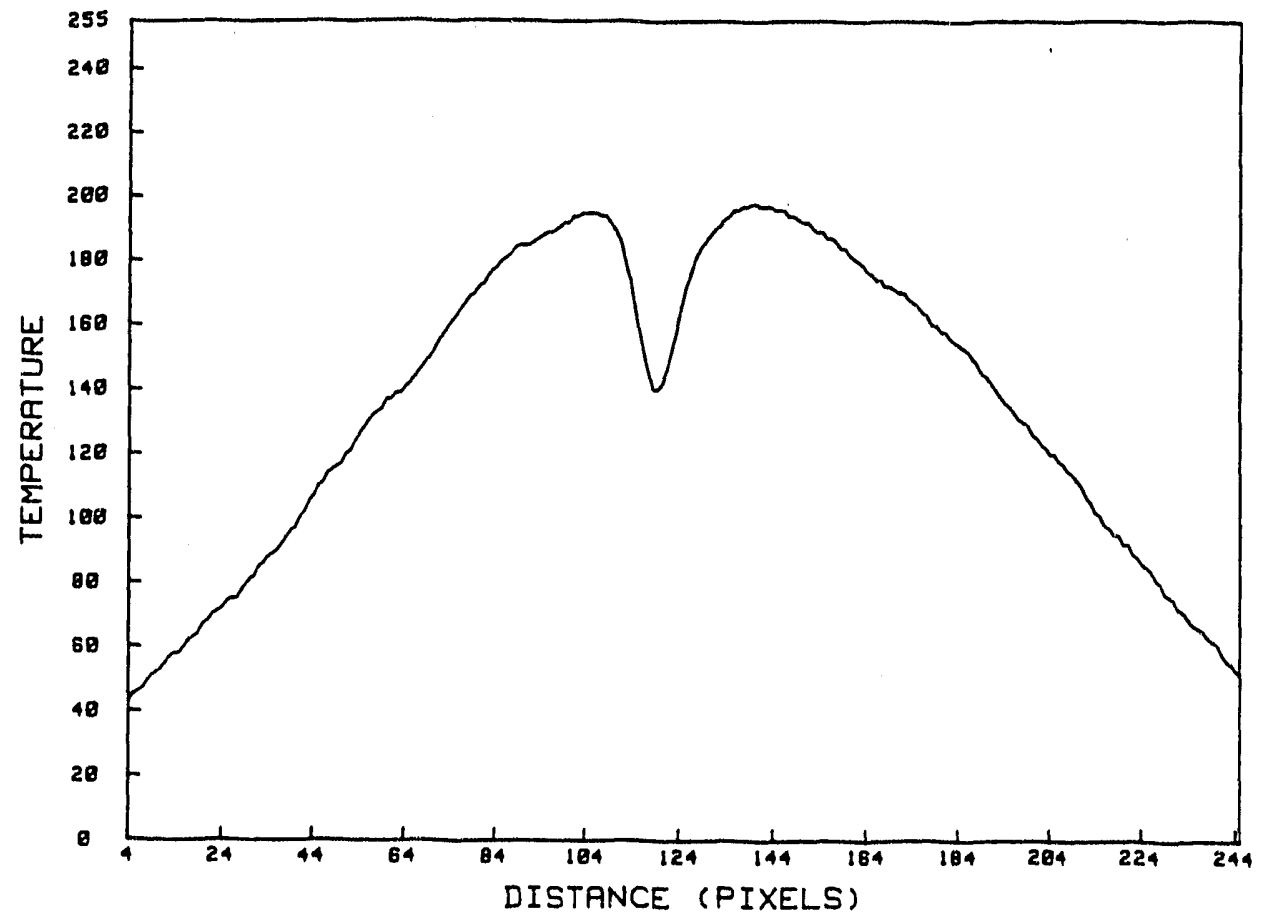

Figure 27. Infrared Intensity Distribution across a Joint 


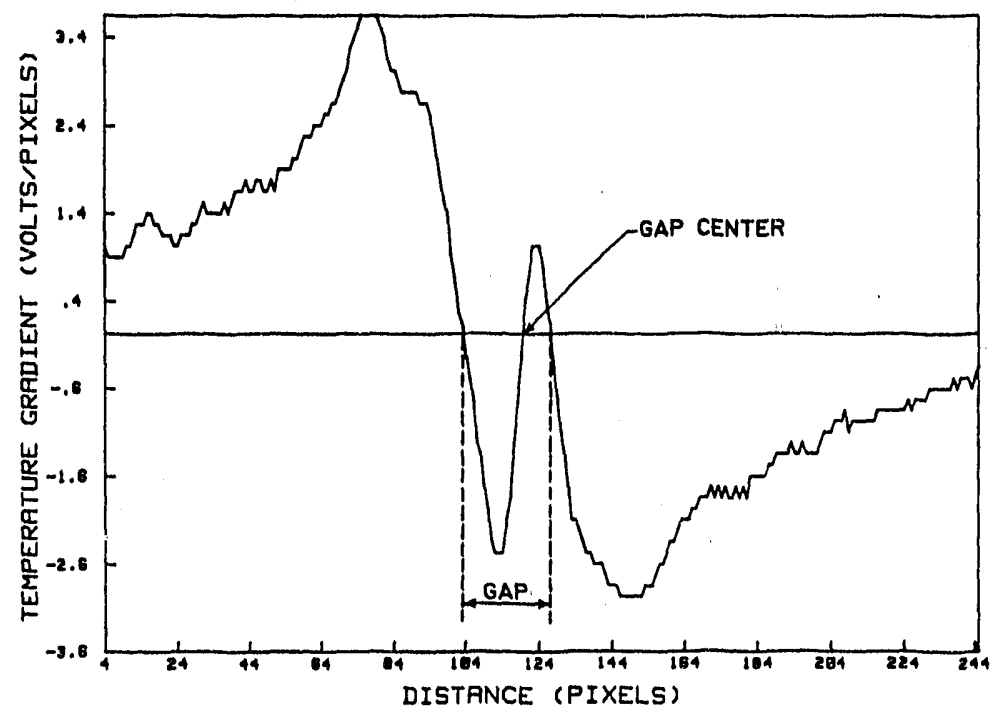

Figure 28. First Derivative of the Infrared Intensity Distribution across a Joint

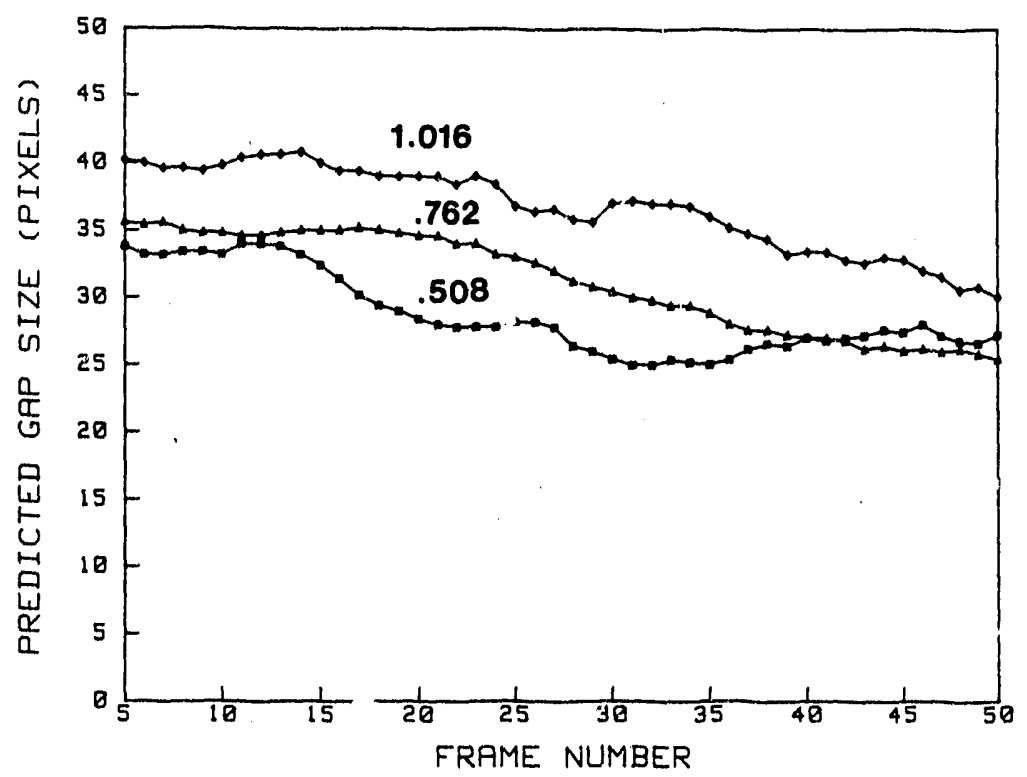

Figure 29. Comparison of Predicted Gap Sizes

1. $-0.508 \mathrm{~mm}, 2 . \Delta-0.762 \mathrm{~mm}$ and $3 .-1.016 \mathrm{~mm}$ 


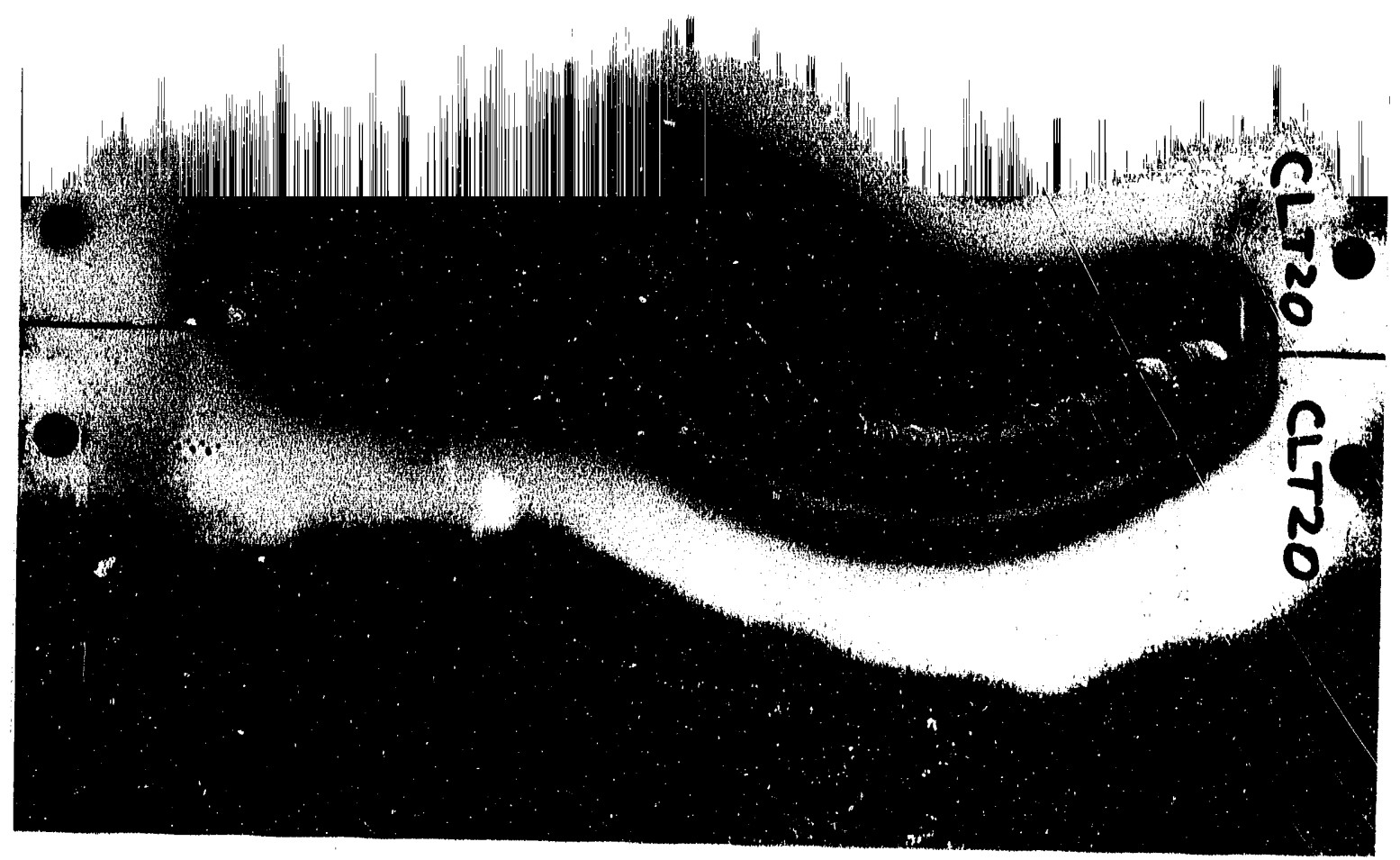

Figure 30. Tracking of Joints with a Gap

\section{III.10 Summary of Experimental Results:}

On the basis of the results obtained during the third year, the following conclusions were arrived at:

- Surface temperature distributions predicted from numerical simulation represented those obtained experimentally

- Shielding gas composition strongly influences not only the temperature distribution but also the temperature gradient and depth of penetration

- The weld pool front determined using the temperature gradient technique bears close resemblance to the actual weld

- Minor eleinents have the unique effect of altering the temperature gradient even when all the weld process parameters are kept constant

- The joint gap determination technique allows excellent seam tracking even with curved joints containing gaps

- The bead width computed along a line transverse to the direction of torch motion shows promise for on-line penetration control 


\section{III.11 Publications and Presentations:}

Publications:

1. Banerjee, P., S. Nagarajan and B. A. Chin, "Weld Quality Control in Gas Tungsten Arc Welding Processes", [Proc. Conf.], The 1991 National Science Foundation Design and Manufacturing Systems Conference, Austin, TX, January 9-11, 1991, p143-147.

2. Nagarajan, S., P. Banerjee and B. A. Chin, "Thermal Imaging for Weld Quality Control in Arc Welding Processes", Transport Phenomena in Materials Processing, ASME, HTD-Vol. 146, November 1990, p171-178.

3. Groom, K. N., S. Nagiarajan and B. A. Chin, "Automatic Single V-groove Welding Utilizing Infrared Images for Error Detection and Correction", Welding Journal, December 1990, v69, no.12, p441s-445s.

4. Nagarajan, S., P. Baneirjee, W. H. Chen and B. A. Chin, "Control of the Welding Process Using Infrared Sensors", , IEEE Transactions on Robotics and Automation, accepterd July 1991.

5. Nagarajan, S. and B. A. Chin, "On-Line Weld Position Control for Fusion Reactor Welding", Submitted for Publication in Journal of Nuclear Materials, September 1991.

6. Banerjee, P. and B. A. Chin, "Infrared Thermography for Nondestructive Monitoring of Weld Penetration Variations", Accepted for Publication in Proceedings, 1992 Japan-USiA Symposium on Flexible Automation, April 1992.

Presentations:

1. "Weld Quality Control in Gas Tungsten Arc Welding", P. Banerjee, S. Nagarajan and B. A. Chin, Poster Presentation, The 1991 NSF Design and Manufacturing Systems Conference, Austin, TX, January 9-11, 1991.

2. "Infrared Sensors in Robotic Welding", Chapter Meeting, Instrumentation Society of America, Birmingham Chapter, November 12, 1990.

3. "Thermal Imaging for Weld Quality Control in Arc Welding Processes", S. Nagarajan, P. Banerjee and B. A. Chin, ASME Winter Annual Meeting 1990, Dallas, TX.

4. "On-Line Weld Position Control in Arc Welding Processes", S. Nagarajan and B. A. Chin, Alabama Materials Research Conference, Birmingham, AL, September 25-26, 1991.

Poster Presentations:

1. "On-Line Detection and Control of Weld Penetration During Automated Gas Tungsten Arc Welding", P. Banerjee and B. A. Chin, Alabama Materials Research Conference, Birmingham, AL, September 25-26, 1991. 
2. Monitoring GTA Weld Puddle Geometry Using Infrared Measured Surface Gradients", S. M. Govardhan and B. A. Chin, Alabama Materials Research Conference, Birmingham, AL, September 25-26, 1991.

3. "Weld Quality Control in Gas Tungsten Arc Welding Processes", P. Banerjee, S. Nagarajan and B. A. Chin, The 1991 National Science Foundation Design and Manufacturing Systems Conference, Austin, TX, January 9-11, 1991, p143-147.

\section{III.12 Awards}

1990 J. F. Lincoln Award for Student Research in Welding Technology, S. Nagarajan and $P$. Banerjee.

1990 TMS (The Minerals, Metals and Materials Society) Award for the Outstanding Student Research Paper, P. Banerjee.

1991 Caroline Carr Award, Sigma Xi National Scientific Honorary, S. Nagarajan 


\section{REFERENCES}

1. Irving, B., "Weld Quality Helps Cadillac Win the Malcolm Baldrige Award", Welding Journal, March 1991, v70, no.3, p57-59.

2. Schliepper, F. J. and M. Green, "Radioscopy Offers Flexibility, Speed in Weld Inspection", Welding Journa1, v70, no.3, p61-65.

3. Cullison, A., B. Irving and M. R. Johnsen, "Controlling Weld Quality: It's One Tough Job", Welding Journal, June 1991, v70, no.6, p31-44.

4. Siewert, T. A. and G. L. Franke, "Analysis and Characterization of Commercial Welding Fluxes", Welding Journal, July 1990, v69, no.7, p247s$255 \mathrm{~s}$.

5. 01 son, D. L. and T. A. Siewert, "Present Consumable Technology Advances into the $21^{\text {st }}$ Century, Welding Journal, November 1990, v69, no.11, p37-40.

6. Lyttle, K. A. and W. F. G. Stapon, "Select the Best Shielding Gas Blend for the Application", Welding Journal, November 1990, v69, no.11, p21-27.

7. Stenbacka, N., "The Influence of Shielding Gas on Cored Wires", Welding Journa1, v69, no.11, p43-45.

8. Kryslak, K. F. and F. M. Bhadha, "Shielding Gas Purification Improves Weld Quality", Welding Journa1, v69, no.11, p47-49.

9. Francis, R. E., J. E. Jones and D. L. Olson, "Effect of Shielding Gas Oxygen Activity on Weld Metal Microstructure of GMA Welded Microalloyed HSLA Stee1, Welding Journa1, v69, no.11, p408s-415s.

10. Lugscheider, E. and W. Tillman, "Development of New Active Filler Metals in a Ag-Cu-Hf System", Welding Journal, v69, no.11, p416s-421s.

11. Rekus, J. F., "Managing Welding Hazards in Confined Spaces", Welding Journa1, Ju7y 1990, v69, no.7, p27-34.

12. Meckley, J. A. and A. Petroski, "Developing Welding Skills for Today's Technology", Welding Journal, September 1990, v69, no.9, p71-73.

13. Kvidah1, L. G., "Welding Technology Developments for Marine Appliations", Welding Journal, August 1990, v69, no.8, p25-29.

14. Baujat, V. and C. Charles, "Submarine Hull Construction Using NarrowGroove GMAW", Welding Journal, August 1990, v69, no.8, p31-35.

15. Oh, Y. K., "Low Dilution Electroslag Cladding for Shipbuilding", Welding Journal, v69, no.8, p37-44.

16. West, T. C., "Wet Welding Electrode Evaluation for Ship Repair", Welding Journal, v69, no.8, p46-56. 
17. Irving, B., "GTA WeTders Put the Finishing Touches on the Fins for the Patriot Missile", Welding Journal, May 1991, v70, no.5, p71-74.

18. Cullison, A., "Welding Gives a Wild Ride to Theme Parks Around the World", Welding Journal, March 1988, v67, no.3, p37-40.

19. Papritan, J. C. and S. C. Helzer, "Statistical Process Control for Welding", Welding Journal, March 1991, v70, no.3, p44-48.

20. "Camera Would Monitor We1d-Pool Contours", NASA Tech-Briefs, January 1990, v14, no.1, p26-27.

21. McGough, M. S. and C. Burgoon, "Visual Monitoring of Remote Welding Operations", Welding Journal, December 1990, v69, no.12, p23-28.

22. NASA Tech Briefs, Apri1 1990, v14, no.4, "Optical Arc-Length Sensor for TIG Welding", p72.

23. Sugitani, Y., Y. Nishi and T. Sato, "Intelligent Robot Controls Penetration and Bead Height", Welding Journal, December 1990, v69, no.12, p31-38.

24. Sugitani, Y., Y. Nishi and T. Sato, "Intelligent Arc Welding Robot with Simultaneous Control of Penetration Depth and Bead Height", [Proc. Conf.] Recent Trends in Welding Science and Technology, May 14-18, 1989, Gatlinburg, TN, p923-928.

25. Griffin, M. D., R. T. Cunningham and R. Eskanazi, "Vision-Based Guidance for an Automated Roving Vehicle", Proceedings AIAA Guidance and Control Conference, August 7-9, 1978, Palo A7to, CA paper 78-1294.

26. Vanderbrug, G. J., J. S. Albus and E. Barkmeyer, "A Vision System for Real Time Control of Robots", Proceedings of $9^{\text {th }}$ International Sysmposium on Industrial Robots, Washington DC, March 1979.

27. Vaisband, Y. S., et al., "A Television System for Automatically Guiding Electrodes along Butt Welds", Automatic Weld, July 1970, v24, no.7, p47.

28. Jolly, W. D., "The Application of Acoustic Emission to In-Process Inspection of Welds", Materials Evaluation, June 1970, p135.

29. Romre11, D. M., "Acoustic Emission Weld Monitoring of Nuclear Components", Welding Journal, p81s

30. Reilly, R., "Real-Time Weld Quality Monitor Controls GMA Welding", Welding Journal, March 1991, v70, no.3, p36-41.

31. Mech, S. J. and T. E. Michaels, "Development of U1trasonic Examination Methods for Austenitic Stainless Steel Weld Inspection", Materials Evaluation, July 1977, p93. 
32. Adler, L., K. V. Cook, H. L. Whaley and R. W. McClung, "Flaw Size Measurement in a Weld Sample by Ultrasonic Frequency Analysis", Materials Evaluation, March 1977, p44.

33. Adler, L., K. V. Cook, H. L. Whaley and R. W. Mcclung, "The Pe?ationship between Uitrasonic Rayleigh Waves and Surface Residual Stress", Naterials Evaluation, July 1977, p93.

34. Carlson, N. M., J. A. Johnson and D. C." Kunerth, "Control of GMAW: Detection of Discontinuities in the Weld Pool", Welding Journal, July 1990 , v69, no.7, p256s-263s.

35. Umeagukwu, C. et a1., "U1trasonic Seam Tracking in the Vicinity of an Operating Welding Torch", Materials Evaluation, April 1990, v48, no.4, p466-470.

36. Arsicault, M. and J. P. Lallemand, "Joint Tracking with a Self-Teaching System", Welding Journal, December 1990, v69, no.12, p41-45.

37. Edmonds, D. P., G. M. Goodwin and G. M. Slaughter, "Development of Automated Pipe and Tube Welding Techniques for Aluminum", Welding Journal, February 1977.

38. Goldberg, G. and R. Karlen, "Seam Tracking and Height Sensing - An Inductive System for Arc Welding and Thermal Cutting", Metal Construction, December 1980, v12, no.12, p668.

39. Scott, J. L. and H. Brandt, "Adaptive Feed Forward Digital Control of GTA Welding", Welding Journal, March 1982, v61, no.3, p36.

40. Asada, $H$. and $H$. Hanafusa, "An Adaptive Tracing Control of Robots and its Application to Automatic Welding", Joint Automatic Control Conference, 1980, FAT-A.

41. Abraham, R. G. and L. Y. Shum, "Robot Arc Welder iwth Contouring Teach Mode", Proceedings of $5^{\text {th }}$ International Conference on Industrial Robots, September 1975, p293.

42. Willett, T. J. and B. Ruscher, "Intelligent Tracking Techniques", SPIE February 1980, v219, no.2, p173.

43. Green, R. G., "Mechanizing Arc and Resistance Welding", Tooling and Production, October 1979, p80-85.

44. Yodoshima, N. and H. Takagi, "OnLine Adaptive Control of Narrow Gap CO Welding with Industrial Television Camera", Joint Automatic Control Conference, 1980, FA7-F.

45. King, F. J., P. Hirsch, "Seam Tracking System with the Arc as Sensor", Advances in Welding Process, [Proc. Conf.] Fourth International Conference, The Welding Institute, 1978, p193. 
46. Cook, G. E., "Through-the-Arc Sensing for Arc Welding", [Proc. Conf.] 10 Conference on Production Research and Technology, SAE, February 28-March 2, 1983, Detroit, MI, p141-151.

47. Prinz, F. B. and J. Hoburg, "Sensors for Seam Characterization in Robotic Arc Welding", Proceedings of Winter Meeting of ASME, Phoenix, AZ, 1982, p278-287.

48. Chickering, B. and L. Fass, "Robotic Welding and Machine Vision Combine to Meet Manufacturing Demands", Welding Journal, November 1987, v66, no.11, p42-43.

49. Cook, G. E., et al., "Control of an Electric Welding Arc", IEEE publication 77, CHO 1233-6 Reg. III, Apri1 1977, p36.

50. Hichen, G. K., N. D. Stucki and H. W. Randall, "Application of Magnetically Controlled Welding Arcs", April 1976, p264.

51. Jayarajan, T. N. and C. E. Jackson, "Magnetic Control of Gas Tungsten Arc Welding Process", Welding Journal, August 1972, p377s.

52. Converti, J., Y. Dror, D. E. Hardt, K. Masubuchi, H. M. Paynter and W. C. Unkel, "Improvement of Welding by In-Process Sensing and Control", Progress Reports one-three, Contract \# DE - ACO2-79ER10474.A000, October 1980.

53. Bachelis, J. A., et al., "Movement of the Electric Arc in a Magnetic Field", Automatic Weld, 1966, 19(40), p43.

54. Mandelberg, C. L., et al., "Control of Arc Welding with the help of a Travelling Magnetic Field", Automatic Weld, 1976, 29(9), pl.

55. Guile, A. E., "Magnetic Fields in Arc Welding", IEEE Conference on Gas Discharges, no. 70, 1970, p489.

56. Guile, A. E., "The Magnetic Movement of Short Arcs with Reference to Arc Welding Problems", British Welding Journa1, 1966, 13, no.6, p357.

57. Vroman, A. R. and H. Brandt, "Feedback Control of GTA Welding Using Puddle Width Measurement", Welding Journal, September 1976.

58. Friedman, E., "Analysis of Weld Puddle Distortion and Its Effect on Penetration", Welding Journal, June 1978, pl61s.

59. Savage, W. F., E. F. Nippes and F. J. Zanner, "Determination of GTA Weld Puddle Configurations by Impulse Decanting", Welding Journal, July 1978, p20ls.

60. Apps, B. L., et a1., "A Note on the Behavior of Liquid Metal Under the Arc", British Welding Journal, July 1963, p348. 
61. Woods, R. A. and D. R. Milner, "Motion in the Weld Pool in Arc Welding", Welding Journal, November 1971, p348.

62. Cook, G. E. and W. M. McCampbe11, "System Maintains Constant Penetration During Fusion Welding", NASA Brief No.67-10091, April 1967.

63. Ramsey, P. W., J. J. Chyle, J. N. Kuhr, P. S. Myers, M. Weiss and W. Groth, "Infrared Temperature Sensing Systems for Automatic Fusion Welding ", Welding Journal, August 1963, p337s.

64. Malmuth, N. D., W. F. Hail1, B. I. Davis and C. D. Rosen, "Transient Thermal Phenomena and Weld Geometry in GTAW", Welding Journal, September 1974 , p338s.

65. Lukens, W. E. and R. A. Morris, "Infrared Temperature Sensing of Cooling Rates for Arc Welding Control", Welding Journal, January 1982, v61, no.1, p27.

66. Green, D. R., "Principles and Applications of Emittance-Independent Infrared Nondestructive Testing", Applied Optics, September 1968, V7, no.9, p1779.

67. Green, D. R. and J. A. Hassberger, "Infrared Electro-Thermal Examination of Stainless Steel", March 1977, Materials Evaluation, p39.

68. McCampbel1, W. M., et al., "Development of Weld Intelligence System", Welding Journal, March 1966, v45, no.3, p139s.

69. Eskenazi, R. and J. M. Wilf, "Low Level Processing for Real Time Image Analysis", JPL Report 79-79 NASA Contract NAS7-100.

70. Horn, B. K. P., "Artificial Intelligence and the Science of Image Understanding", Computer Vision and Sensor Based Robots, G. G. Dodd and L. Rossol (ed.), Plenum Press, New York, 1979, p69.

71. Vanderbrug, G. J. and R. N. Nagel, "Image Pattern Recognition in Industrial Inspection", NBS Report NBSIR 79-1764, September 1979.

72. Evans, I. M., R. Kirsch and R. N. Nagel (ed.), "Workshop in Standards for Image Pattern Recognition", NBS Special Publication 500-8, June 1976.

73. Spicer, R. A., W. A. Baeslack III and T. J. Kelly, "Elemental Effects on GTA Spot Weld Penetration in Cast Alloy 718", Welding journal, August 1990 , v69, no.8, p285s-288s.

74. Xiao, Y. H. and G. den Ouden, "A Study of GTA Weld Pool 0scillation", Welding Journal, August 1990, v69, no.8, p289s-293s.

75. Sunde11, R. E., L. Harris, D. W. Walsh, H. Solomon, S. Correa and W. F.Savage, "Minor Element Effects on Gas Tungsten Arc Weld Penetration", General Electric Report No. 86SRD013, 1986. 
76. Heiple, C. R., J. R. Roper, R. T. Stranger and R. J. Aden, "Surface Active Element Effects on the Shape of GTA, Laser, and Electron Beam Welds", Welding Journal, March 1983, (3), 72-s to 77-s.

77. Zacharia, T., A. H. Eraslan and D. K. Aidun, "Modelling of Non-Autogenous Welding", Welding Journal, January 1988. v67, no.1, pl8s-27s.

78. Zacharia, T., A. H. Eraslan and D. K. Aidun, "Modelling of Autogenous Welding", Welding Journal, March 1988, v67, no.3, p53s-62s.

79. Ule, R., Y. Joshi and E. B. Sedy, "A New Technique for Three Dimensional Transient Heat Transfer Computations of Autogenous Gas Tungsten Arc Welding", Metallurgical Transactions, 21B(12), 1033-1047, 1990.

80. Chin, B. A., J. S. Goodling and N. H. Madsen, "Infrared Thermography Shows Promise for Sensors in Robotic Welding", Robotics Today, February 1983, p85-87.

81. Chir, B. A., J. S. Goodling and N. H. Madsen, "Infrared Thermography for Sensing the Weld Process", Welding Journal, September 1983, p227-234.

82. Chin, B. A., N. H. Madsen, J. S. Goodling and B. Z. Jang, "Automatic Welding: Infrared Thermography for Sensing the Weld Process", [Proc. Conf.] International Conference on Advanced Automation, Taipei, Taiwan, December 1983, p331-342.

83. Khan, M. A., N. H. Madsen and B. A. Chin, "Infrared Thermography as a Control for the Welding Process", Thermal Infrared Sensing for Diagnostics and Control, Ed: G. J. Burrer, v446, SPIE, 1983, p154-165.

84. Chin, B. A. and N. H. Madsen, "Infrared Sensors for Process Control", [Proc. Conf.], Eleventh Conference on Production Research and Technology, May 21-24, 1984, p85-89.

85. Madsen, N. H., T. T. Lin and B. A. Chin, "Infrared Sensors for Weld Process Control", [Proc. Conf.] Advanced Systems for Manufacturing, SME, 1985, p335-345.

86. Chin, B. A. and N. H. Madsen, "Infrared Sensors for Process Control", Advanced Automation, IEEE, Plenum Press, New York, 1985, p411-429.

87. Wang, $Y$. and B. A. Chin, "On-Line Sensing of Weld Penetration Using Infrared Thermography", Optical Techniques for Industrial Inspection, v665-34, SPIE, June 1986, p314-320.

88. Lin, T. T., K. Groom, N. H. Madsen and B. A. Chin, "Infrared Sensing Techniques for Adaptive Robotic Welding", Modeling and Control of Casting and Welding Processes, AIME-TMS, 1986, p19-32.

89. Lin, T. T., H. T. Lin and B. A. Chin, "On-Line Control of Surface Contamination During Gas Tungsten Arc Welding", Optical Engineering, May 1988, v27, no.5, p413-419. 
90. Nagarajan, S., W. H. Chen and B. A. Chin, "Infrared Sensing for Adaptive Arc Welding", Welding Journal, November 1989, v68, no.11, p462s-466s.

91. Govardhan, S. M. and B. A. Chin, "Monitoring GTA Weld Puddle Geometry Using Measured Surface Temperature Gradients", [Proc. Conf.] Recent Trends in Welding Science and Technology, Editors: S. A. David and J. M. Vitek, ASM, Materials Park, OH, 1990, p383-386.

92. Nagarajan, S., K. N. Groom and B. A. Chin, "Infrared Sensors for Seam Tracking in Gas Tungsten Arc Welding Processes", [Proc. Conf.] Recent Trends in Welding Science and Technology, Editors: S. A. David and J. M. Vitek, ASM, Materials Park, OH, 1990, p951-956.

93. Chen, W. H., P. Banerjee and B. A. Chin, "Study of Penetration Variations in Automated Gas Tungsten Arc Welding", [Proc. Conf.] Recent Trends in Welding Science and Technology, Editors: S. A. David and J. M. Vitek, ASM, Materials Park, OH, 1990, p517-522.

94. Nagarajan, S., P. Banerjee and B. A. Chin, "Weld Pool Size and Position Control Using IR Sensors", [Proc. Conf.] 1990 NSF Design and Manufacturing Systems Conference, SME, Tempe, AZ, January 1990, p607-615.

95. Nagarajan, S. and B. A. Chin, "IR Image Analysis for On-Line Monitoring of Arc Misalignment in Gas Tungsten Arc Welding Process", Accepted for Publication in Materials Evaluation, February 1990.

96. Chen, W. H. and B. A. Chin, "Monitoring Weld Penetration Using Infrared Sensing Techniques", Welding Journal, May 1990, v69, no.5, p181s-185s.

97. Chin, B. A., S. Nagarajan and P. Banerjee, "Infrared Sensors for Robotic Adaptive Welding", [Proc. Conf.] International Robots and Vision Automation Conference, Detroit, MI, June 5-7, 1990, p14-50 to 14-60.

98. Nagarajan, S., P. Banerjee and B. A. Chin, "Thermal Imaging for Weld Quality Control in Arc Welding Processes", Transport Phenomena in Materials Processing, ASME, HTD-Vo1. 146, November 1990, p171-178.

99. Groom, K. N., S. Nagarajan and B. A. Chin, "Automatic Single V-groove Welding Utilizing Infrared Images for Error Detection and Correction", Welding Journal, December 1990, v69, no.12, p441s-445s.

100. Banerjee, P., S. Nagarajar and B. A. Chin, "Weld Quality Control in Gas Tungsten Arc Welding Processes", [Proc. Conf.], The 1991 National Science Foundation Design and Manufacturing Systems Conference, Austin, TX, January 9-11, 1991, p143-147.

101. Nagarajan, S., P. Banerjee, W. H. Chen and B. A. Chin, "Control of the Welding Process using Infrared Sensors", Accepted for Publication in IEEE Transactions on Robotics and Automation, July 1991.

102. "Weld Penetration and Defect Control", Second Year Annual Report, Grant DEFG0788ER12817A, May 1990. 

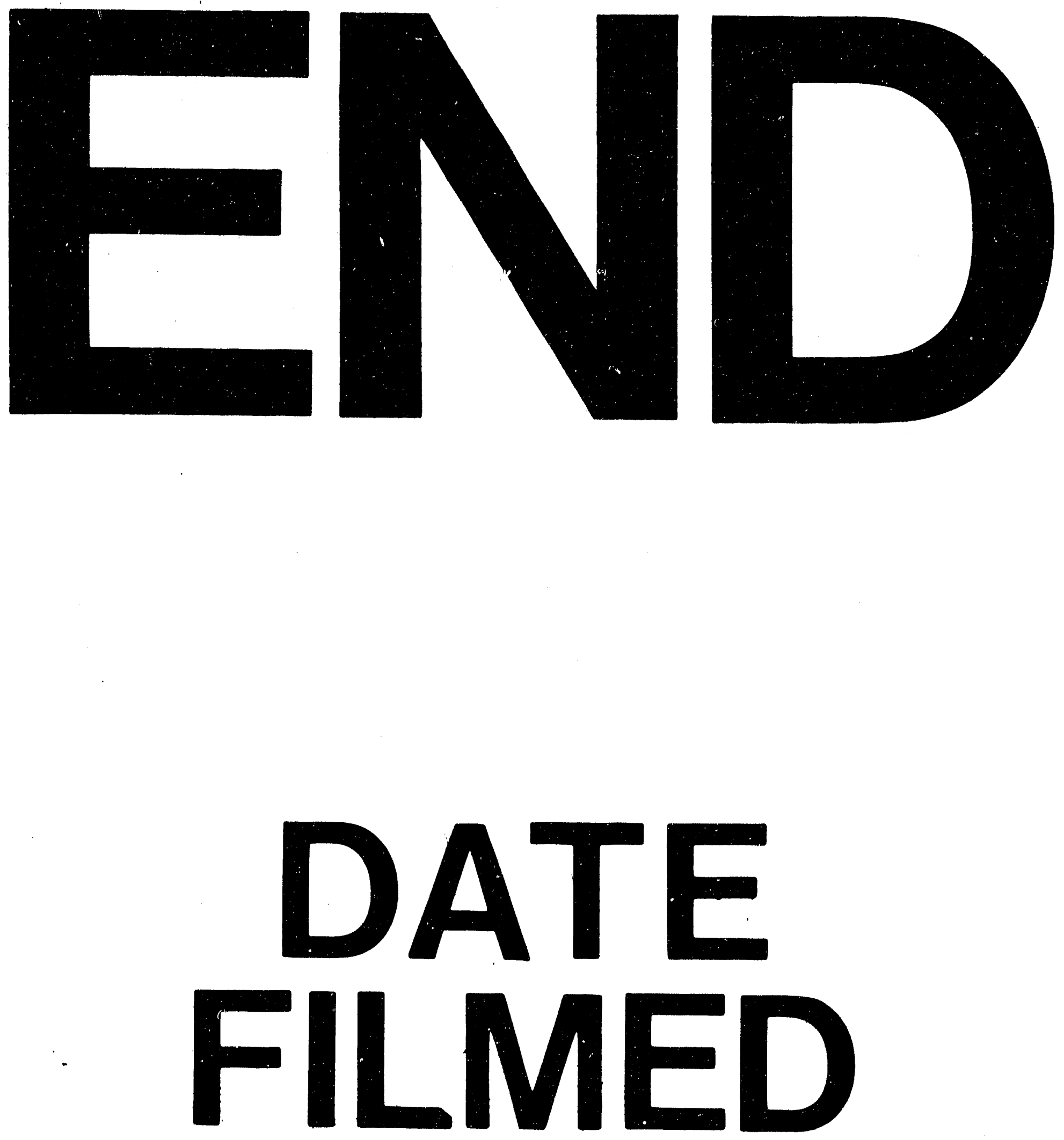

t

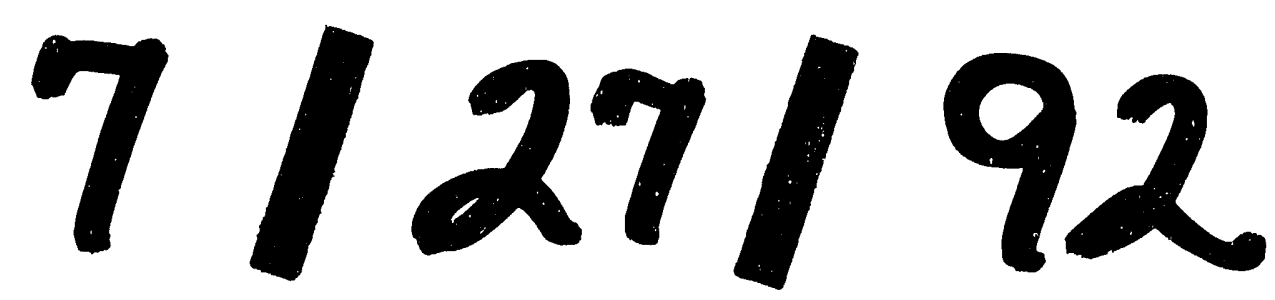


